\title{
UM SISTEMA DE NAVEGAÇÃO PARA UM SGBD BASEADO EM UM MODELO SEMÂNTICO
}

\author{
Paulo Augusto dos Santos
}

\author{
Orientador: \\ Prof. Dr. Paulo Cesar Masiero
}

Dissertação apresentada ao Instituto de Ciências Matemáticas de São Carlos - USP, como parte dos requisitos para obtenção do título de Mestre em Ciências de Computação e Matemática Computacional. 
Aos meus pais Pedro e Eunice que sempre me apoiaram em meus estudos.

À Solange Mota pelo carinho e compreensão durante a realização deste trabalho. 


\section{Agradecimentos}

Ao Professor Dr. Paulo Cesar Masiero pela orientação, apoio e atenção que sempre me dispensou durante a elaboração deste trabalho.

Ao Professor Eduardo Tadao Takahashi pela colaboração na especificação da interface e pelo auxílio financeiro recebido junto ao PABI-ETHOS.

Aos amigos da USP-São Carlos e IPS-Campinas pela amizade e contribuição dada durante a realização deste trabalho. 
Este trabalho foi possível, graças ao apoio das entidades: CNPq, CAPES e PABI-ETHOS. 


\section{Resumo}

Neste trabalho apresenta-se uma extensa revisão bibliográfica sobre os sistemas de navegação em bases de dados ("browsers"), levantando-se e comparando-se as características dos principais sistemas desse tipo encontrados na literatura.

Os resultados dessa análise foram utilizados para projetar e implementar um sistema desse tipo dentro do ambiente Damokles, que é centrado num SGBD baseado em um modelo de dados semântico, desenvolvido especialmente para uso em ambientes de desenvolvimento de software. O sistema : ..plementado permite a navegação no esquema da base de dados e também em suas instâncias. Foram utilizados recursos gráficos para apresentar o esquema da base de dados e facilitar a interação com o usuário.

Descrevem-se também as principais decisões de projeto do sistema implementado, bem como ilustra-se o seu uso através de uma sessão demonstrativa, utilizando-se como exemplo uma base de dados não muito complexa. 


\begin{abstract}
In this thesis a comprehensive bibliographic analysis about data base browser systems is made. The major facilities of these systems are assessed and compared.

Using the knowledge acquired from that analysis a Browser System has been designed and implemented within the Damokles environment, which focuses on a DBMS based on a semantic data model. Damokles has been developed to be used in software development environments. The browser developed allows navigation through the data base schema as well as through the object instances. Graphical facilities have been utilized in the system's interface aiming at a visual, user-friendly interact ${ }_{\lrcorner}$on between the user and the system.

The major design decisions are also described and the system's usability is demonstrated walking through a user session browsing a not complex data base.
\end{abstract}




\section{Conteúdo}

1 Introdução 1

1.1 Considerações Gerais . . . . . . . . . . . . . . 1

1.2 Definição do Problema . . . . . . . . . . . 3

1.3 Organização do Trabalho ............... 5

$\begin{array}{lll}2 & \text { Revisão Bibliográfica } & 7\end{array}$

2.1 Considerações Iniciais . . . . . . . . . . . . . 7

2.2 Modelos Convencionais . . . . . . . . . . . 7

2.2 .1 Modelo de Rede . . . . . . . . . . . . 8

2.2 .2 Modelo Hierárquico . . . . . . . . . . 8

2.2.3 Modelo Relacional . . . . . . . . . . . . 11

2.3 Modelos Semânticos . . . . . . . . . . . 13

2.3.1 O Modelo Entidade-Relacionamento. . . . . . . . . 14

2.3.2 O Modelo de Dados Semântico (SDM) . . . . . . 16

2.4 Browsers para Modelos Semânticos . . . . . . . . . 18

2.4.1 LID: "Living In a Database" . . . . . . . . . . 18 
2.4.2 GUIDE: Grafical User Interface for Database Exploration 22

2.4.3 SKI : Semantics-Knowledgeable Interface . . . . . . 25

2.4.4 ISIS: Interface for a Semantic Information System . . . 29

2.5 Avaliação Comparativa dos Browsers Revisados . . . . . . 32

2.6 Considerações Finais . . . . . . . . . . . . . . 34

3 Um "Browser" para o SGBD Damokles 36

3.1 Considerações Iniciais . . . . . . . . . . . . . 36

3.2 O Modelo de Dados do SGBD Damokles . . . . . . . . 37

3.3 O Modelo de Dados Usado no Browser . . . . . . . . . . 42

3.4 Arquitetura Geral do Sistema . . . . . . . . . . . . 47

3.5 Dados Sobre a Implementação Realizada . . . . . . . . . . . 49

3.6 Considerações Finais . . . . . . . . . . . . . 50

4 Detalhes da Implementação Realizada 51

4.1 Considerações Iniciais . . . . . . . . . . . . . . . 51

4.2 Visão Geral da Interface . . . . . . . . . . . . . 51

4.3 Exemplo de Utilização do Browser . . . . . . . . . . . 53

4.4 Limitações do Browser Implementado . . . . . . . . . . . 68

4.5 Considerações Finais . . . . . . . . . . . . . 68

5 Conclusão $\quad 71$

5.1 Avaliação do Protótipo . . . . . . . . . . . 71 
5.2 Sugestão para Evolução do Protótipo e Novas Pesquisas . . . . 72

Bibliografia

74

A Exemplo de definição de um esquema

77

B Entrada Para a Criação do Diagrama do Modelo de Dados Usado no Browser

81 


\section{Lista de Figuras}

2.1 Diagrama de Backman Estendido . . . . . . . . . . 9

2.2 Modelo Hierárquico Genérico . . . . . . . . . . . 10

2.3 Relação não normalizada . . . . . . . . . . . . . . 12

2.4 Relações normalizadas . . . . . . . . . . . . 12

2.5 Representação no Modelo Entidade-Relacionamento . . . . . 15

2.6 LID: modelo de dados utilizado no exemplo . . . . . . . 19

2.7 LID: menu de entidades . . . . . . . . . . . . . 20

2.8 LID: instâncias de entidade e relacionamento . . . . . . . . 21

2.9 GUIDE: modelo de dados utilizado no exemplo . . . . . . 25

2.10 SKI: visão geral da interface . . . . . . . . . . . . 27

2.11 SKI: relacionamento entre entidades . . . . . . . . . . 28

2.12 ISIS: visão geral da interface . . . . . . . . . . . 30

2.13 ISIS: seleção de uma classe . . . . . . . . . . . . . . . 32

2.14 ISIS: uma classe com atributos e suas instâncias . . . . . . . 33

2.15 Tabela de comparação dos browsers . . . . . . . . . 35 
3.1 Exemplo modelado em DODM . . . . . . . . . . . . . . 42

3.2 Exemplo modelado segundo as notações de Hara . . . . . . . 44

3.3 Exemplo modelado segundo as notações do browser . . . . . 46

3.4 Arquitetura Geral do Sistema . . . . . . . . . . 47

4.1 "Menu de fundo" da janela principal do browser . . . . . . . 54

4.2 Janela principal do browser após selecionada a opção "Ver esquema BD" . . . . . . . . . . . . . . 55

4.3 Menus associados à janela do nível geral $\ldots \ldots \ldots \ldots$

4.4 "Menu de janela" associado a janela do nível geral . . . . 57

4.5 "Menu de fundo" da janela do nível geral $\ldots \ldots \ldots \ldots 8$

4.6 Janela "pop-up" associada à op̧̧ão "selecionar entidade" . . . 60

4.7 Janela de nível geral ap' seleção da entidade "body" . . . . . 61

4.8 "Menu de entidade" . . . . . . . . . . . . 63

4.9 Escolha da opção "atributos" no "menu de entidade" . . . . 64

4.10 Nível de instâncias selecionado . . . . . . . . . . . 65

4.11 "Menu de relacionamento" . . . . . . . . . . . 66

4.12 Seleção da op̧̧ão "nome relacionamento" no "menu de relacionamento" . . . . . . . . . . . . . . . . 67

4.13 Seleção da opção "entidades participantes" no "menu de relacionamento" . . . . . . . . . . . . . . . . . 69 


\section{Capítulo 1}

\section{Introdução}

\subsection{Considerações Gerais}

Nos últimos 20 anos, a área de Gerenciamento de Base de Dados tornou-se de vital importância no campo da Ciência da Computação, pois o volume de informações armazenadas em computadores tem aumentado considera,velmente, o que exigiu a criação de novas regras para administrar o armazenamento e a recuperação das informações. Inicialmente, foram criados e utilizados os modelos em rede e o hierárquico para a modelagem dos sistemas de Base de Dados. No início dos anos 70, duas direções opostas de pesquisas foram iniciadas em base de dados: o modelo relacional e o desenvolvimento de modelos semânticos.

O modelo relacional caracterizou-se por separar a representação lógica dos dados da implementação física. Assim, a utilização da formalização matemática: cálculo e álgebra relacional, possibilitou o desenvolvimento de linguagens de consulta não procedimentais (ou não algorítmicas) poderosas e uma variedade de resultados teóricos importantes.

Os modelos semânticos foram introduzidos inicialmente como ferramentas para projetar modelos de dados conceituais: um esquema pode ser primeiro projetado em um modelo semântico de alto nível e então ser 
traduzido para um dos modelos tradicionais, para ser posteriormente implementado. A ênfase inicial do modelo semântico foi permitir a criação de modelos com um conteúdo semântico maior para os mesmos modelos convencionais.

Segundo Hull [HuK_87], os modelos semânticos são mais complexos que o modelo relacional e encorajam uma visão mais navegacional do relacionamento dos dados.

A primeira publicação sobre modelos semânticos apareceu em 1974 [Abi_74]. A área amadureceu durante a década subsequente com o desenvolvimento de muitos modelos e originou um grande corpo de pesquisa relacionada.

$O$ resultado central de pesquisa de modelagem semântica tem sido o desenvolvimento de mecanismos poderosos para representar o aspecto estrutural dos dados. Mais recentemente, pesquisadores de bases de dados tem voltado suas atenções em direção à incorporação dos aspectos comportamentais (ou dinâmicos) dos dados para modelar formalismos; esse trabalho está sendo influenciado pelo paradigma orientado a objetos, de linguagens de programação [HuK_87]. Além disso, os modelos semânticos são adequados para representação visual, o que tem contribuído para o desenvolvimento de muitas interfaces gráficas para esse tipo de base de dados. Essas interfaces são oferecidas em muitas variedades e para diferentes tipos de aplicações. Também são importantes para aperfeiçoar a utilização e receptividade dos sistemas de base de dados.

Um "browser" é um tipo particular de interface criado para facilitar a interação entre usuários e bases de dados armazenadas por um Sistema de Gerenciamento de Base de Dados. Assim, um browser é utilizado para executar buscas exploratórias e permite visualizar o esquema e as instâncias de uma Base de Dados, bem como seu inter-relacionamento. Idealmente, o browser não deveria requerer familiaridade com a base de dados à qual se está tendo acesso ou ter pré-concebido o objetivo final a ser alcançado. Um browser é projetado com o objetivo de ser facilmente utilizável, com um modelo de interface homem-máquina muitas vezes intuitivo para o usuário.

Enquanto utiliza o browser, o usuário ganha conhecimento do 
conteúdo e organização do ambiente pesquisado. No final, a pesquisa termina com êxito ou é abandonada.

As interfaces surgiram da necessidade de comunicação entre o homem e a máquina. Essa comunicação é de vital importância nos sistemas desenvolvidos atualmente, porque dela depende o sucesso e a aceitação do sistema, bem como a satisfação do usuário.

Conforme caracterizou Fisher em [Fis_89] : "O sucesso de novos sistemas de computadores é julgado menos sobre velocidade de processamento e tamanho de memória e mais sobre a qualidade de sua capacidade de comunicação". O sucesso de um sistema depende muito do envolvimento do usuário. Esse envolvimento cria interesse e motivação do usuário, tornando assim mais fácil a aceitação de um sistema.

Atualmente, para se desenvolver uma boa interface são utilizados recursos da computação gráfica, pois a habilidade do ser humano em extrair informações significantes de uma figura é muito maior do que a habilidade pára ler informações alfa-numéricas. Consequentemente, tem-se desenvolvido muitos sistemas utilizando técnicas de computação gráfica como uma forma eficiente para a interação homem-máquina. A.ssım, são desenvolvidos sistemas com melhor aceitação do usuário, podendo reduzir substancialmente o tempo de aprendizado e a taxa de erros. Outra vantagem é o aumento do desempenho e da produtividade dos usuários, possibilitando redução nos custos gerais de uso do sistema.

\subsection{Definição do Problema}

Durante o desenvolvimento do programa de Mestrado foi implementado um protótipo de um browser para um Sistema de Gerenciamento de Base de Dados (a ser referenciado como SGBD) orientado a objetos. Este sistema é o SGBD DAMOKLES [DiG_86] (DAtabase Management system Of KarLsruhe for Environments for Software engineering), que foi desenvolvido pela Universidade de Karlsruhe e surgiu no âmbito do projeto alemão UNIBASE, com o objetivo de dar apoio ao desenvolvimento de software. O desenvolvimento de um browser para o SGBD Damokles era fundamental, 
pois este sistema não possui ainda uma linguagem de consulta para a Base de Dados. Assim, toda vez que o usuário necessitar de alguma informação da BD precisará desenvolver um programa de aplicação para obter o seu conteúdo.

Segundo uma classificação apresentada por Dittrich[Dit_86], Damokles é uma base de dados orientada a objetos, com enfoque estrutural, isto é, o seu modelo de dados, chamado DODM (Design Object Data Model), permite a descrição de objetos complexos manipulados por operações genéricas, ou seja, que se aplicam indistintamente aos objetos e seus componentes. Os outros enfoques existentes são: o operacional, que permite a definição de tipos abstratos de dados e o comportamental, que engloba as características dos dois enfoques anteriores.

O sistema Damokles foi desenvolvido para dar suporte a ambientes de projeto e os recursos por eles requeridos. Estes recursos são :

- Suporte a versões temporais e alternativas de projeto;

- Relacionamentos entre objetos e/ou versões com cardinalidade arbitrária;

- Um tipo especial de atributo, chamado LONG_FIELD, para o armazenamento de dados não estruturados de comprimento longo;

- Distribuição de múltiplas bases de dados lógicas em uma rede de estações de trabalho e servidores;

- Suporte a transações longas através de um mecanismo de "empréstimo" de objetos de uma base de dados para outra, a fim de trabalhar sobre os mesmos durante um longo período de tempo;

- Mecanismo básico para validação das relações de hierarquia de objetos e cardinalidade das relações.

O sistema possui dois componentes através dos quais o usuário comunica-se com o sistema: a DDL (Data Description Language) e a DML (Data Manipulation Language). A DDL é a linguagem utilizada para descrever as estruturas dos dados e os estados permitidos da base de dados, isto 
é, o seu esquema. A DML de uma base de dados fornece operações para recuperar e manipular os dados armazenados.

Um browser para o SGBD Damokles é muito importante para o ambiente, pois tem-se uma maneira fácil, eficiente e prática para consultar o esquema da base de dados, juntamente com suas intâncias. É útil também para o usuário certificar-se de que as operações que um programa de aplicação executou na base de dados foram realmente realizadas e de forma correta.

\subsection{Organização do Trabalho}

No capítulo 1 foram apresentadas as idéias gerais do contexto em que estão situados os modelos semânticos e a necessidade de densenvolvimento de interfaces para SGBDs, em especial os browsers, que tèm importante utilização nesses SGBDs. Na seção 1.2 foi apresentada uma descrição sucinta do SGBD Damokles, utilizado na implementação do browser desenvolvido para esta Dissertação de Mestrado. Também foi apresentada uma 'escrição dos recursos necessários em um SGBD para dar apoio a ambientes de projetos.

O capítulo 2 apresenta os pontos relevantes do estudo bibliográfico realizado para o desenvolvimento deste trabalho. Descrevem-se as características principais dos modelos de dados convencionais e também dos modelos semânticos. É apresentado um resumo dos principais browsers encontrados na literatura e também é apresentada uma tabela comparando os browsers encontrados.

No capítulo 3 é apresentado um browser para o SGBD Damokles, é descrito o modelo de dados DODM, utilizado pelo SGBD Damokles, o modelo de dados usado na implementação do browser apresentado e a Arquitetura Geral do sistema. Nesse capítulo são também oferecidos alguns dados sobre a implementação realizada.

É ilustrado no capítulo 4 uma sessão de uso do browser, sendo apresentada uma visão geral da interface, um exemplo de uma sessão utilizando o browser desenvolvido, limitações e possiveis extensões para o sis- 
tema implementado:

Para finalização do trabalho são apresentadas no capítulo 5 as conclusões finais: uma avaliação do protótipo desenvolvido e sugestões para evolução do protótipo e futuras pesquisas. 


\section{Capítulo 2}

\section{Revisão Bibliográfica}

\subsection{Considerações Iniciais}

A revisão bibliográfica apresentada neste capítulo tem o propósito de apresentar os modelos de dados utilizados nas implementações dos SGBDs com ênfase nos modelos semânticos. São apresentadas as descrições de alguns browsers encontrados na literatura.

O capítulo foi dividido em 4 seçôes: na seção 2.2 são apresentados os modelos convencionais. Os modelos semânticos são apresentados na seção 2.3. Posteriormente, na seção 2.4, apresenta-se a bibliografia referente aos browser que encontram-se descritos na literatura. Na seção 2.5 é apresentada uma tabela comparando os browsers encontrados na literatura.

\subsection{Modelos Convencionais}

Os Sistemas de Gerenciamento de Bases de Dados surgiram da necessidade de se trabalhar com um grande volume de dados. Assim, foi preciso desenvolver mecanismos para a manipulação, armazenamento e recuperação desses dados. 
Surgiram vários modelos e técnicas para implementação de um SGBD, e cada implementação sempre se atém a uma maneira particular de se considerar a passagem da representação de dados do mundo real para o domínio da representação da base de dados. $O$ domínio de representação de dados de uma base de dados é chamado Modelo de Dados ou Modelo de uma Base de Dados.

Inicialmente foram desenvolvidos dois modelos de dados para serem usados nas implementações dos SGBDs: o Modelo de Rede e o Modelo Hierárquico.

\subsubsection{Modelo de Rede}

O Modelo de Rede foi o primeiro a ser tratado em ampla escala e a ter alguns padrões estabelecidos. Nesse modelo, parte-se do conceito de que as informações são armazenadas em arquivos, onde os dados com estruturas iguais são agrupados. Cada arquivo é composto de um conjunto de registros, todos com a mesma estrutura. Cada registro é composto de campos e esses campos fodem conter informações ou podem se referir a informações que estão armazenadas em outros registros.

Com o Modelo de Rede, normalmente usa-se a notaçào de Bachman[Bac_69] para expressar simbolicamente a estrutura de dados de uma dada aplicação (figura 2.1).

Em um diagrama de Bachman são representados todos os registros e os campos que os constituem, sendo que os campos usados como chave de identificação são grifados. Os relacionamentos que existem são identificados através de interligações entre os registros.

\subsubsection{Modelo Hierárquico}

Em Sistemas de Gerenciamento de Bases de Dados que usam este modelo, os registros podem ser agrupados de duas maneiras. Inicialmente, faz-se o agrupamento dos registros em arquivos, sendo que todos os re- 


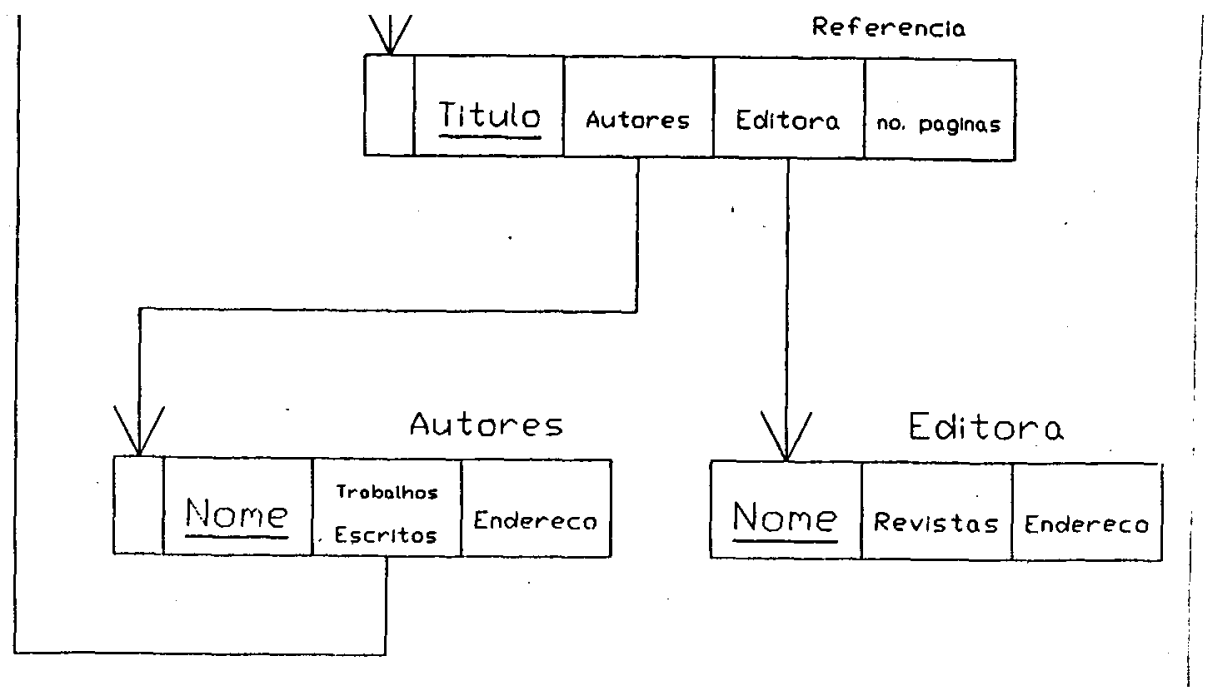

Figura 2.1: Diagrama de Backman Estendido

gistros de cada arquivo devem ter o mesmo formato e, a seguir, agrupam-se os registros em tipos hierárquicos, correspondendo à hierarquia de ocorrências, ou de identificação e acesso dos registros.

Nesse modelo, os registros mantém entre si relacionamentos semelhæntes aos que ocorrem no Modelo de Rede, porém o registro que origina um relacionamento é chamado registro pai, e o outro é chamado de registro filho.

Em um Modelo Hierárquico existe a restrição de que um registro pai pode estar relacionado com um ou muitos registros filhos (um pai pode ter muitos filhos), porém um registro filho pode estar relacionado a apenas um registro pai (figura 2.2 ).

A forma de implementação física do Modelo Hierárquico está bastante ligada ao esquema conceitual, uma vez que as duas formas de agrupamento apresentadas por esse modelo se referem à forma como as estruturas são fisicamente mantidas. Isso se deve à necessidade de se representar através do modelo hierárquico situações do mundo real que nem sempre estão estruturadas de maneira hierárquica. Para isso, o modelo prevê a existência de representação de dois modelos conceituais simultâneos para um mesmo pro- 


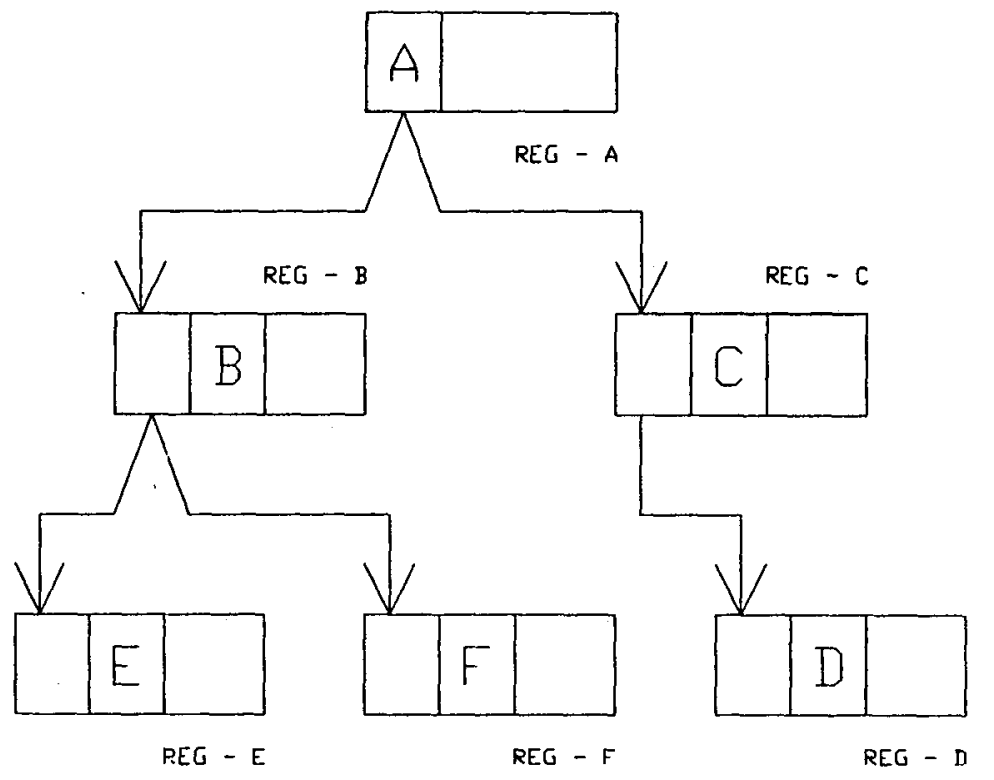

Figura 2.2: Modelo Hierárquico Genérico

blema do mundo real, que se denominam Hierarquia Primária e Hierarquia Secundária.

O modelo conceitual que representa a Hierarquia Primária é usado pelo sistema de Gerenciamento de Base de Dados para determinar a estrutura física da base de dados, e é dessa forma que o acesso aos dados é efetuado. A Hierarquia Secundária, que em algumas implementações pode até constituir um conjunto de várias hierarquias, fornece caminhos de acesso lógicos alternativos, que podem ser usados para a interface entre o SGBD e o programa de aplicação.

Dessa forma, o Modelo Hierárquico não está restrito a aplicações que tenham uma estrutura hierárquica, pois usando-se modelos conceituais que envolvem a representação de hierarquias secundárias, este pode ser usado em aplicações que envolvam um número limitado de características de rede. No entanto, deve-se levar em conta que, a menos que os acessos efetuados o sejam através da hierarquia primária, os demais são mais caros em termos de tempo de acesso. 


\subsubsection{Modelo Relacional}

O Modelo Relacional tem seus fundamentos originados na teoria matemática da álgebra das relações e foi desenvolvido a partir dos trabalhos de Codd[Cod_70], numa tentativa de obter um modelo para SGBDs que apresentasse para o projetista de aplicação uma interface de nível mais alto do que as apresentadas pelas interfaces dos SGBDs existentes na época. O conceito matemático da álgebra das relações é a operação de produto cartesiano de dois ou mais conjuntos:

\section{$A \times B \times C \times \ldots$}

do qual escolhem-se as n-uplas ordenadas que constituem cada relação.

O modelo relacional apresenta a organização dos dados em forma de tabelas, denominadas relações, onde cada uma agrupa informações que mantém a mesma estrutura (registros, segundo a denominação adotada nos modelos de rede e hierárquico), e que na terminologia adotada pelo modelo relacional são chamadas de tuplas. Correspondendo ao conceito matemático de que uma relação é um conjunto, vem o fato de que cada tupla em uma relação é única, não podendo existir em uma relação mais do que uma tupla contendo os mesmos valores.

Um conceito muito importante no modelo relacional é o de normalização. A normalização consiste de um conjunto de regras bem estabelecidas, que permitem identificar e eliminar redundâncias que ocorrem durante a modelagem dos dados. Como um exemplo de uma relação não normalizada, tem-se a relação "Ordens de Compra" na figura 2.3. Essa relação não está normalizada, pois existem atributos cujos valores podem ser obtidos diretamente através de outros atributos da mesma relação, como é o caso do "Nome do Fornecedor". Essa situação não é desejável, uma vez que a duplicação de informações pode levar a inconsistência de dados.

A figura 2.4 apresenta uma versão normalizada dessas mesmas informações. O processo de normalização geralmente leva à criação de mais relações, tal como ocorre no exemplo, em que uma relação é separada em 


\begin{tabular}{|c|c|c|c|c|c|}
\hline \multirow[b]{2}{*}{$\begin{array}{l}\text { Número } \\
\text { da ordem }\end{array}$} & \multicolumn{4}{|c|}{ Relação de Ordens de Compra } & \multirow[b]{2}{*}{ Quantidade } \\
\hline & Data & $\begin{array}{l}\text { Nome do } \\
\text { Fornecedor }\end{array}$ & $\begin{array}{l}\text { Número do } \\
\text { Fornecedor }\end{array}$ & $\begin{array}{l}\text { Núm. do } \\
\text { Produto }\end{array}$ & \\
\hline 0101 & $20 / 02 / 88$ & Industria $\mathrm{ABC}$ & 10 & 2743 & 2 \\
\hline 0101 & $20 / 02 / 88$ & Industria $\mathrm{ABC}$ & 10 & 2751 & 11 \\
\hline 0124 & $12 / 05 / 88$ & Industria $\mathrm{ABC}$ & 10 & 3015 & 12 \\
\hline 0234 & $19 / 06 / 88$ & Reis Ind. Com. & 06 & 1573 & 200 \\
\hline 0234 & $19 / 06 / 88$ & Reis Ind. Com. & 06 & 1591 & 50 \\
\hline
\end{tabular}

Figura 2.3: Relação não normalizada

\begin{tabular}{|c|c|c|c|c|c|}
\hline Relação & de Ordens & $e C$ & npra & Relação d & Fornecedones \\
\hline $\begin{array}{l}\text { Número } \\
\text { da ordem }\end{array}$ & Data & & $\begin{array}{l}\text { lero do } \\
\text { lecedor }\end{array}$ & $\begin{array}{l}\text { Número do } \\
\text { Fornecedor }\end{array}$ & $\begin{array}{l}\text { Nome do } \\
\text { Fornecedor }\end{array}$ \\
\hline 0101 & $20 / 02 / 88$ & & 10 & 06 & Reis Ind. Corn. \\
\hline 0124 & $12 / 05 / 88$ & & 10 & 10 & Industria $\mathrm{ABC}$ \\
\hline 0234 & $19 / 06 / 88$ & & 06 & & \\
\hline & & & lação de $\operatorname{Pr}$ & odutos - & \\
\hline & $\begin{array}{l}\text { Nún } \\
\text { da o }\end{array}$ & & $\begin{array}{l}\text { Número do } \\
\text { Produto }\end{array}$ & Quantidac & \\
\hline & 01 & & 2743 & 2 & : \\
\hline & 01 & & 2751 & 11 & \\
\hline & 01 & & 3015 & 12 & \\
\hline & 02 & & 1573. & 200 & \\
\hline & 02 & & 1591 & 50 & \\
\hline
\end{tabular}

Figura 2.4: Relações normalizadas

três. Porém, assegura uma maior consistência de dados, bem como, em geral, diminui a quantidade de espaço necessário para armazenar as informações.

Uma implementação de SGBD usando o modelo relacional apresenta para o projetista de aplicações operações de alto nível, fundamentadas nas operações da teoria dos conjuntos, tais como Seleção, Projeção, União e Divisão. Todas essas operações têm como resultado a criação de outras relações, com atributos e tuplas obtidos a partir das relações usadas como operandos. Uma base de dados relacional armazena as relações descritas no modelo conceitual da base e as relações que são criadas por operações são 
mantidas em uma área de trabalho própria de cada aplicação, somente existindo durante o tempo em que a aplicação está sendo executada [Tra_86].

\subsection{Modelos Semânticos}

As estruturas de dados usadas nos modelos convencionais (rede, hierárquico e relacional) são relativamente restritas àquelas usadas para a representação física dos dados no computador; basicamente, as visões que se tem dos dados é a de um conjunto de registros, onde cada campo do registro contém um valor imprimível ou um apontador para um campo onde esse dado está armazenado. Assim, esses modelos são frequentementes referenciados como sendo baseados em registro.

Os SGBDs desenvolvidos baseados nos modelos convencionais têm em vista principalmente aplicações comerciais, onde geralmente tem-se um volume muito grande de dados estruturalmente idênticos. Por outro lado, surgiu a necessidade de se trabalhar com dados que não possuem a mesma homogeneidade estrutur: :-, isto é, surgiram as aplicações não comerciais dos sistemas de computação, onde os dados têm estruturas mais complexas e necessitam de novos modelos que os representem melhor.

Os Modelos Semânticos foram desenvolvidos para proporcionar um alto nível de abstração para a modelagem de dados, permitindo ao projetista da base de dados pensar nos dados da maneira que corresponda mais diretamente à forma como o dado surgiu, ou à visão intuitiva dele no mundo real.

Inicialmente, os modelos semânticos foram introduzidos como ferramentas para projeto de esquemas de dados e incluíam tipos fundamentais de relacionamentos encontrados em uma aplicação típica de base de dados. Como um resultado desse fundamento, os modelos de dados e os sistemas baseados em semântica proporcionaram as seguintes vantagens sobre o sistema tradicional orientado a registro [HuK_87]:

(i) aumento da separação dos componentes conceitual e físico; 
(ii) diminuição da sobrecarga semântica dos tipos de relacionamento;

(iii) disponibilidade de mecanismos convenientes para abstração.

(i) O aumento da separação dos componentes conceitual e físico foi conseguido, pois, nos modelos orientados a registro, o caminho de acesso para o usuário final tende a imitar diretamente a estrutura lógica do esquema da base de dados.

Tem-se que, nos modelos de rede e hierárquico, os caminhos de acesso correspondem diretamente às ligações físicas de baixo nível entre os registros. No modelo relacional o usuário deve simular ponteiros, comparando identificadores ordenados para navegar de uma relação a outra (tipicamente usando o operador Join). Em contraste, os atributos dos modelos semânticos podem ser usados como um ponteiro conceitual.

(ii) A segunda vantagem citada dos modelos semânticos reside no fato de que os modelos orientados a registros são sobrecarregados semanticamente, pois têm-se muitos tipos de relacionamentos diferentes que devem ser representados com um mesmo construtor. Assim, alguns modelos semânticos tiveram como objetivo básico proporcionar uma família de construtores coerentes para representar de forma estrutural os tipos de informações que o modelo relacional pode representar através de restrições.

(iii) Os modelos semânticos oferecem uma variedade de mecanismos convenientes para visão e acesso ao esquema em diferentes níveis de abstração. Uma dimensão da abstração oferecida por esses modelos refere-se ao nível de detalhes com que as partes do esquema podem ser vistas. Outra dimensão da abstração oferecida por modelos semânticos é o grau de modularidade proporcionado por eles. É fácil isolar informações sobre um dado tipo, seus sub-tipos e seus atributos.

\subsubsection{O Modelo Entidade-Relacionamento}

Entre os modelos semânticos que surgiram na literatura, o Modelo Entidade-Relacionamento foi um dos pioneiros e tem tido maior 


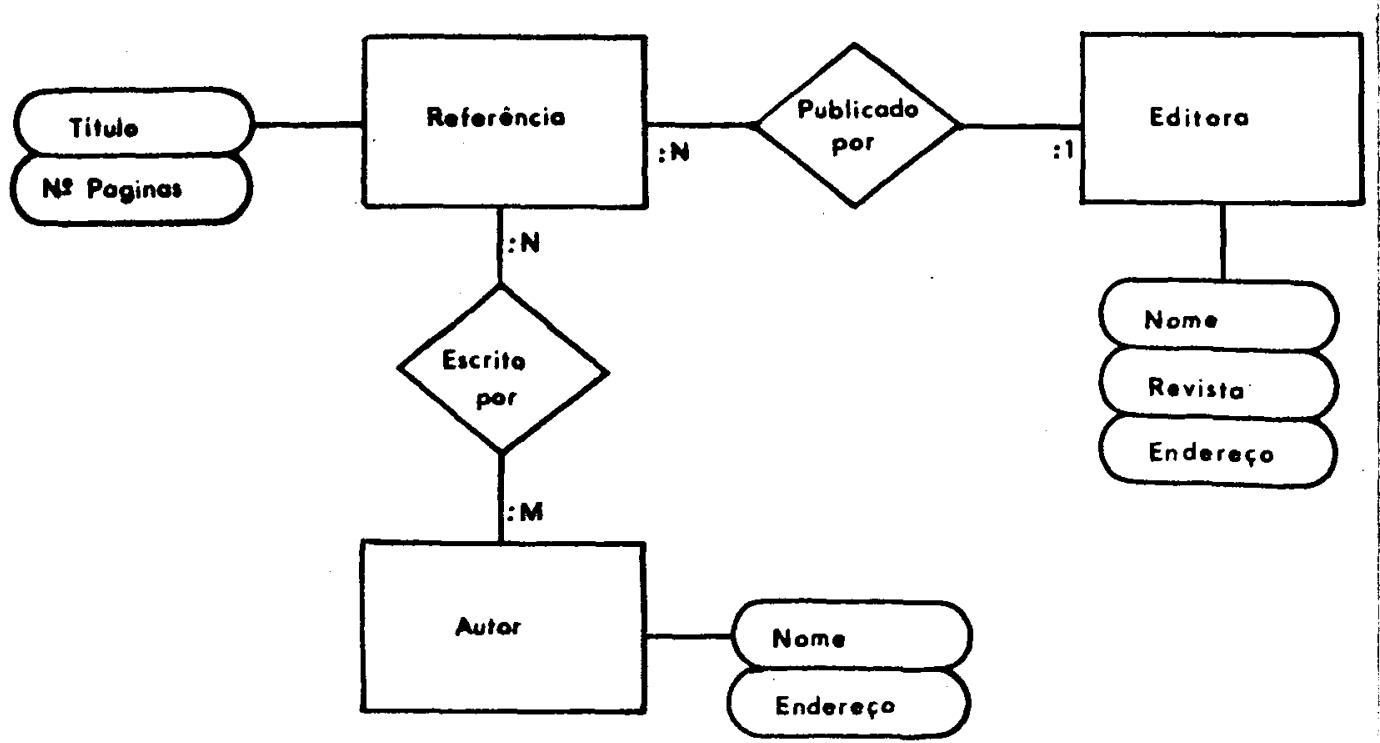

Figura 2.5: Representação no Modelo Entidade-Relacionamento

aceitação e difusão. Esse modelo foi proposto por Chen [Che .76] como uma extensão ao modelo relacional, com o propósito de trazer para o modelo mais informação sobre a estrutura dos dados representados, ou seja, com o propósito de aumentar o conteúdo semântico do modelo.

O Modelo Entidade-Relacionamento descreve um sistema através da representação de suas entidades, através dos relacionamentos existentes entre as entidades, e dos atributos que especificam as entidades e relacionamentos modelados. Além disso, as entidades e relacionamentos que tenham atributos iguais são agrupados, constituindo os conjuntos de entidades e conjuntos de relacionamentos. Cada entidade em um conjunto de entidade deve ser identificada univocamente através de um conjunto de atributos.

De maneira diferente do modelo relacional, o Modelo EntidadeRelacionamento determina que os relacionamentos existentes entre as entidades sejam especificados. Os relacionamentos podem ser de qualquer cardinalidade, ou seja, existem relacionamentos de cardinalidade $1: 1,1: \mathrm{N}$ e N:M (figura 2.5). 
O esquema conceitual de uma base de dados que emprega esse modelo é feito descrevendo-se os conjuntos de entidades e os conjuntos de relacionamentos relevantes para o sistema. Esses dados devem ser armazenados e deve-se indicar quais são os atributos que cada conjunto possui.

0 esquema de um modelo de dados usando o Modelo EntidadeRelacionamento é normalmente representado através de um diagrama, denominado Diagrama de Entidade-Relacionamento, onde usa-se um retângulo para representar as entidades, um losango para representar os relacionamentos, e elipses para representar os atributos.

Devido ao conteúdo semântico apresentado pelo Modelo Entidade-Relacionamento ser substancialmente maior do que os apresentados pelos demais modelos, tem-se tornado prática comum o uso do Diagrama de Entidade-Relacionamento para a modelagem dos dados de uma aplicação e, posteriormente, efetuar-se a tradução dessa representação para diagramas voltados a uma particular implementação do SGBD que se pretende usar.

\section{3? O Modelo de Dados Semântico (SDM)}

O Modelo de Dados Semântico (Semantic Data Model - SDM) [HMc_81] é constituído por um formalismo parả descrever um esquema de dados para base de dados. Segundo os autores desse modelo, as estruturas de dados que podem ser representadas pelos modelos convencionais não suportam o desenvolvimento e a manutenção de Base de Dados complexas, por terem capacidade muito limitada de representação semântica. Foi proposto o Modelo de Dados Semântico como uma alternativa para a modelagem de dados, capaz de representar uma grande quantidade de informações semânticas.

Os princípios básicos para a modelagem de uma situação do mundo real usando o formalismo proposto por SDM, apoiam-se nos conceitos de "entidade", que correspondem aos objetos existentes no ambiente a ser modelado, sejam eles reais ou abstratos, e "classes", que são coleçôes de entidades que formam conjuntos de entidades com mesmo significado, $e$ às quais pode-se dar nomes. Toda classe tem uma coleção de atributos, que são usados para descrever as entidades que compõem essa classe. Os atri- 
butos podem ser de dois tipos: Atributos de Membros, que são associados a cada entidade que compõe a classe; e Atributo de Classe, que descrevem propriedades da classe tomada como um todo.

As classes são divididas em classes básicas - aquelas que podem ser definidas de forma independente de qualquer outra do esquema de dados; e classe não básicas - aquelas que são definidas em termos de uma ou mais outras classes.

As classes não básicas estão associadas através de conexões inter-classes ("inter-class connections"). Essas conexões inter-classes são divididas em conexões de sub-classes, e conexões de agrupamento.

As conexões de sub-classes indicam que as entidades pertencentes a uma classe podem também fazer parte de sub-classes dessa classe. Assim, uma sub-classe é também uma classe que contém algumas, mas não necessariamente todas, as entidades da classe básica. Uma conexão de subclasse é especificada através de um predicado satisfazendo uma condição definida sobre o valor de um atributo de membro da classe básica.

As conexões de agrupamento permitem expressar classes compostas por outras classes de mais baixo nível (as classes de mais baixo nível são as classes básicas).

Os autores chamam a atenção para o fato de que cada uma das classes não básicas são definidas através de apenas uma única conexão inter-classe, apesar de que frequentemente mais de uma conexão poderia expressar a mesma classe. Isso é proibido sob a alegação de que mais de uma conexão inter-classe seria redundante e traria uma complexidade adicional desnecessária ao esquema.

Os relacionamentos existentes entre as entidades de cada classe são feitos através dos valores de atributos que compõem cada classe, de uma maneira semelhante ao que ocorre no modelo relacional. Assim, especificandose como valor de um atributo em uma classe o mesmo valor de um atributo de identificação em outra classe, o relacionamento fica estabelecido e pode ser usado para ter acesso a outras entidades em outras classes.

É possivel indicar relacionamento entre apenas duas classes, e 
nesse caso, para todo relacionamento é indicado um relacionamento inverso, assim como relacionamentos envolvendo várias classes, sendo que nesse caso um mesmo atributo é usado para comparar a ocorrência de seus valores em várias classes simultaneamente.

Segundo os autores, o SDM não pretende esgotar todas as possibilidades de representação de semântica de dados em esquemas apropriados para bases de dados, mas permitir o que os autores apresentam como relação 80-20, ou seja, atender $80 \%$ das contruções necessárias à representação das bases de dados com apenas $20 \%$ dos recursos disponíveis, e manter o SDM como um formalismo para a representação de esquemas de dados, aberto para futuras extensões que se mostrarem necessárias e adequadas.

Ao leitor interessado em aprofundamento nesse assunto, sugerese [Mel_88], onde é feita uma revisão de características de BD não convencionais, bem como uma descrição de alguns desses SGBDs.

\subsection{Browsers para Modelos Semânticos}

Nesta seção são analisados os principais browsers de interesse para esta dissertação, encontrados na literatura. A finalidade do browser é orientar e encorajar o usuário a explorar e percorrer a meta base de dados para obter uma visão geral dessa base e selecionar partes de seu interesse. É também uma maneira simples de saber como os dados estão armazenados ou foram armazenados na base de dados por um programa de aplicação.

\subsubsection{LID: "Living In a Database"}

O sistema LID [Fog_84] é uma interface de consulta gráfica para uma base de dados, baseada no modelo Entidade-Relacionamento. Esse sistema é representado por uma estrutura que contém o nome do nó, o texto associado e uma lista de nós adjacentes. Uma consulta de um usuário é feita examinando o conteúdo dos nós e movendo-se para nós adjacentes para reunir as informações desejadas. Especificamente, os usuários têm acesso a 


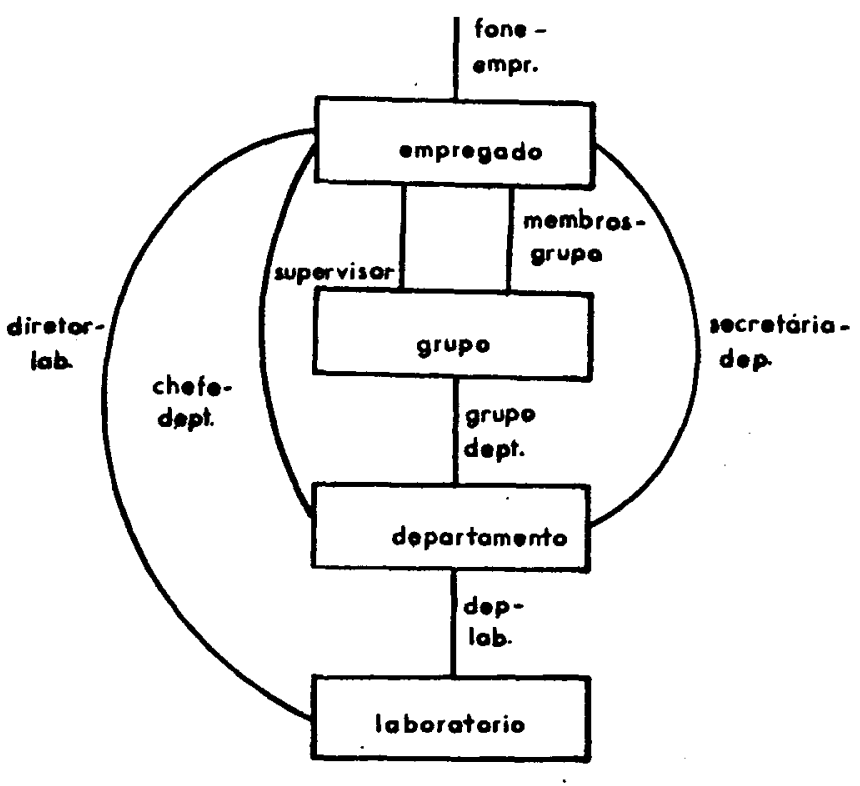

Figura 2.6: LID: modelo de dados utilizado no exemplo

uma tupla específica da base de dados e vêem a base de dados da perspectiva daquela tupla. Consultas simples são respondidas encontrando a tupla apropriada à qual se quer ter ácesso. Consultas mais complexas são expressas através da navegação no conjunto de dados criado pelos relacionamentos.

Em seguida será analisado uma sessão de consulta utilizando o sistema LID. A base de dados da figura 2.6 será utilizada para responder a uma consulta. A sessão inicia mostrando na parte inferior da tela um menu com 3 opcões, correspondendo às 3 opções do mouse. $O$ elemento do menu mais à esquerda é rotulado com "entity menu" e quando é pressionado o botão do mouse correspondente a essa opção, um menu "pop-up" aparece contendo a lista das possíveis entidades a que se pode ter acesso (figura 2.7). Naturalmente, a seleção da base de dados foi feita anteriormente.

Após selecionar a entidade desejada, é mostrada a base de dados da perspectiva de uma tupla particular chamada "tupla corrente". Os valores para os campos da entidade são listados na caixa da tupla corrente no centro da tela. A caixa pequena e o losango conectados à tupla corrente 


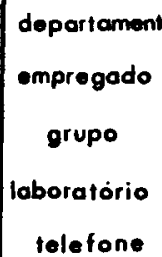

Figura 2.7: LID: menu de entidades

assemelham-se aos símbolos de entidade e ao conjunto de relacionamentos de um diagrama de E-R (figura 2.8), mas existe uma diferença sutil e importante: suas presenças indicam que a tupla corrente está conectada, no mínimo, a uma tupla na entidade "departamento" através do conjunto de relacionamento "secretária-dept".

A idéia básica no sistema LID é: entidade e conjunto de relacionamentos são listados apenas se existe uma instância da tupla corrente no conjunto de relacionamento. Outros conjuntos de relacionamentos podem estar conectados à entidade "empregado" no esquema global, mas desta tupla não se pode ter acesso às tuplas das outras entidades relacionadas, assim, elas estão escondidas. Chama-se "secretária-dept" de caminho e "departamento" de uma entidade caminho.

Quando é selecionada a entidade "empregado", um conjunto de 


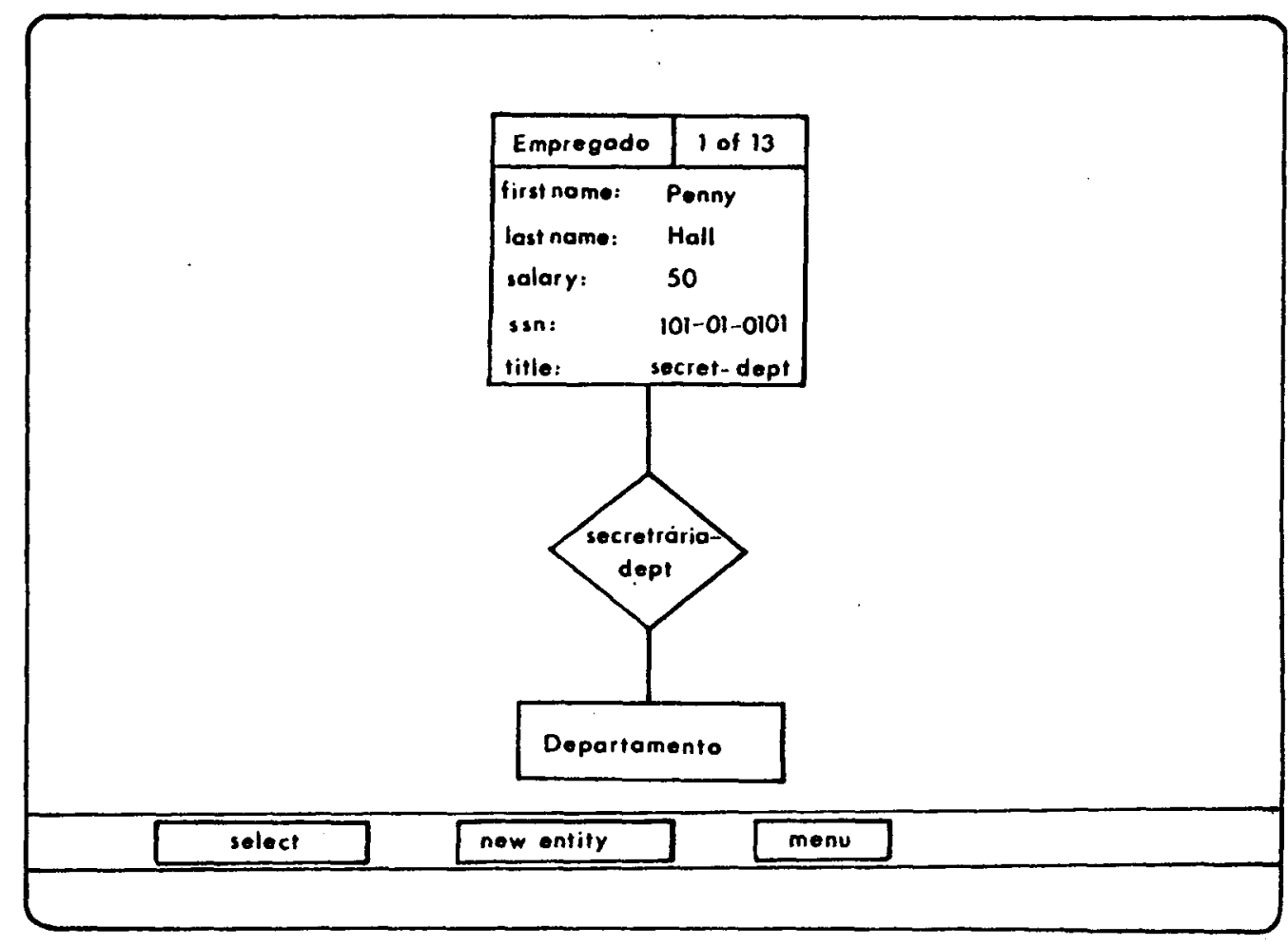

Figura 2.8: LID: instâncias de entidade e relacionamento

tuplas é colocado na lista de tuplas correntes. O número do canto superior direito da caixa da tupla corrente indica o número total de tuplas na lista de tuplas correntes e o número a esquerda desse indica a posição da tupla na lista.

Pode-se percorrer a lista de tuplas correntes usando os comandos "next" ou "previous", ou então, recuperar diretamente outra tupla especificando-se a sua posição. $\mathrm{O}$ comando de pesquisa é chamado movendose o mouse para a caixa da tupla corrente e pressionando a tecla com rótulo "select". Os comandos de seleção são baseados no botão do mouse e também no posicionamento do cursor.

Para selecionar uma dada instância da lista, entra-se com os dados correspondentes aos campos de interesse da tupla desejada. Para navegar em direção a uma entidade desejada, ativa-se o caminho que leva a esta 
entidade pressionando a tecla "select" do mouse.

O sistema LID tem mais limitações que os outros sistemas a serem analisados a seguir, pois permite ao usuário apenas consultar a base de dados, não permitido definição do esquema ou a formulação de uma consulta mais sofisticada. Uma de suas deficiências é que conjuntos de ítens de dados não podem ser manipulados como um item de dado simples.

\subsubsection{GUIDE: Grafical User Interface for Database Exploration}

O sistema GUIDE [WoK_82] é uma interface gráfica para exploracão de uma base de dados. Sua finalidade é fornecer ao usuário um conjunto de recursos em um sistema integrado, para orientar o usuário e facilitar a utilização do sistema.

Um desses recursos proporciona ao usuário menus, ilustacões, exemplos e mensagens de ajuda em qualquer estágio ou formulação da consulta. Assim, dimuinui a responsabilidade do usuário em guardar certos detalhes, como por exemplo nomes, tipos e atributos de um registro, quando quer executar uma consulta.

Outro recurso vem do fato do sistema ser baseado no modelo Entidade-Relacionamento. Assim, o esquema do modelo pode ser apresentado como uma rede de objetos, cada objeto representando uma entidade ou um tipo de relacionamento. Isso dá ao usuário uma visão geral do esquema em qualquer momento. As consultas podem ser formuladas como um caminho na rede das entidades, podendo-se usar cores para indicar a consulta. Uma característica importante desse sistema é que partes do esquema podem ser selecionadas e tornarem-se visiveis ou invisiveis formando assim a base para a implementação de niveis multiplos de detalhes para ajudar no entendimento e uso do esquema da base de dados.

O Usuário pode construir uma consulta em partes e ter resultados intermediários parciais da consulta em qualquer momento.

Para facilitar a manipulação da meta-base de dados e o grande 
número de entidades e seus atributos, duas espécies de diretórios são oferecidos.

O primeiro é chamado "diretório para apresentar hierarquia", o qual pode ser usado para organizar hierarquicamente as entidades em grupos lógicos. $O$ usuário é guiado pelo sistema através desse diretório para localizar partes relevantes do esquema para as quais podem se expressar consultas. Isso é também uma facilidade usada para percorrer e explorar o conteúdo da base de dados.

O segundo tipo de diretório é chamado "diretório hierárquico de atributo" e é usado para organizar atributos de entidades (ou relacionamentos) em grupos similares para o diretório em uso. Cada objeto do tipo entidade ou do tipo relacionamento tem um diretório de atributo.

Outro recurso disponível é uma classificação ("rank") de objetos de acordo com suas "relevâncias" para um grupo particular de usuários. As entidades e os tipos de relacionamentos são ordenados e classificados em grupos de acordo com os interesses dos usuários e a frequência de acesso na consulta. Pode-se ter classificações diferentes para grupos de usuários distintos.

Existem quatro estágios de formulação de consulta no GUIDE: definição do esquema, exploração do esquema, expressão da consulta, e disposição de saída. Definir-se-á em seguida cada um desses estágios.

Estágio de definição dos dados: $\mathrm{O}$ administrador da base de dados oferece informações sobre o esquema durante o estágio de definição. O "lay-out" gráfico do esquema é fornecido ao sistema nesse estágio. São proporcionadas facilidades ao Administrador da Base de Dados para:

- especificar o "layout" gráfico do esquema;

- construir um diretório para apresentar hierarquia do esquema de objetos;

- especificar o nível de importância das entidades e relacionamentos no esquema. 
Estágio de exploração do esquema: Durante esse estágio, o usuário pode usar o diretório para pesquisar as partes mais relevantes do esquema. $\mathrm{O}$ esquema pode ser examinado graficamente em muitos níveis de abstração e serão mostrados apenas os objetos com nível de detalhes acima do especificado.

Estágio de expressão de consulta: Neste estágio, o usuário pode construir a consulta em partes. $\mathrm{O}$ resultado da recuperação de uma consulta parcial à base de dados pode ser mostrado se for desejado. $\mathrm{O}$ usuário pode concentrar-se em muitas partes do esquema mostrado na tela e pode formular a consulta local sobre cada parte. Assim, cada consulta local é completamente independente das outras. A idéia é permitir ao usuário ter uma visão focalizada de pequenas partes do esquema e assim resultados locais podem ser obtidos e entendidos sem ter que compor consultas complexas cobrindo um grande espaço do esquema ao mesmo tempo. 0 usuário pode ligar as consultas locais para formar uma consulta complexa.

Estágio de disposição de saída: Durante este estágio, os resultados podem ser mostrados em várias formas, tais como : grafos, diagramas de barras, etc.

$\mathrm{Na}$ figura 2.9 é apresentado o esquema de uma base de dados. O nível de detalhes (variando de 1 a 5 ) já foi especificado pelo usuário. Assim, o usuário está pronto para expressar uma consulta. A linha que liga as entidades é utilizada para representar a cardinalidade do relacionamento: quando a linha é grossa indica que a entidade que está junto a essa linha tem cardinalidade $\mathrm{N}$, e se a linha for fina, sua cardinalidade no relacionamento é 1 . Por exemplo, o relacionamento "IS IN" entre "PERSON" e "FAMILY" é um relacionameto muitos para um, indicado pela linha grossa entre "PERSON" e "IS IN", e pela linha fina entre "IS IN" e "FAMILY". O usuário pode executar várias consultas locais independentes em um mesmo esquema e cada consulta é representada por uma cor diferente pelo sistema para comunicar graficamente o efeito e o escopo de uma consulta. O sistema oferece comandos para juntar consultas locais para formar uma consulta maior.

O sistema Guide foi implementado utilizando o Modelo Entidade-Relacionamento original, com isto, o conteúdo semântico modelado pelo sistema é menor, pois tem-se extensões desse modelo onde o conteúdo 


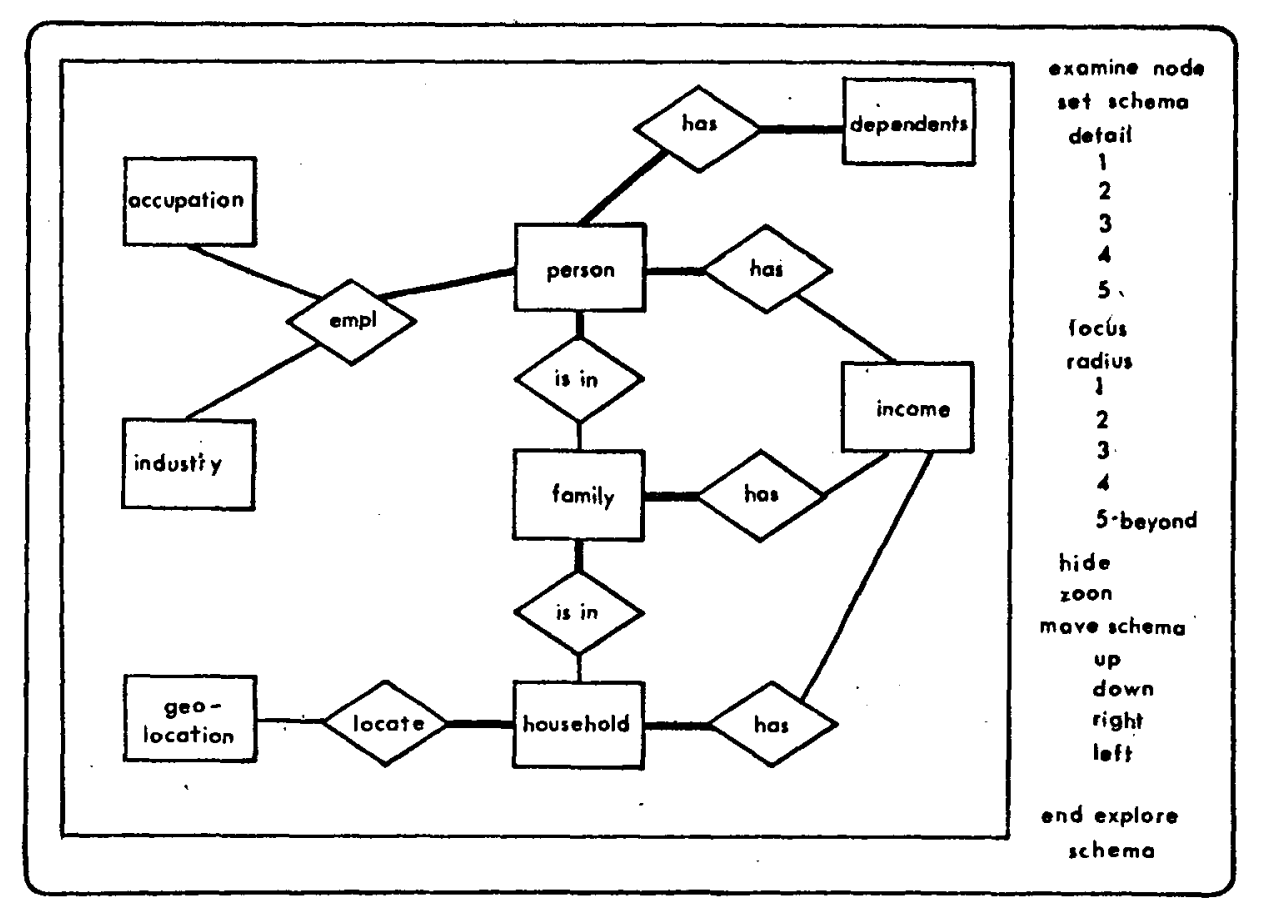

Figura 2.9: GUIDE: modelo de dados utilizado no exemplo

semântico armazenado na BD é maior, como por exemplo, tem-se extensões que suportam os conceitos de Generalização e Agregação. Generalização é um conceito de abstração o qual permite que uma classe de objetos similares seja considerada como um objeto genérico [Smi_77b]. Agregação é um conceito de abstração no qual um relacionamento entre objetos simples (entidades) é visto como um objeto de nível mais alto [Smi-77a].

\subsubsection{SKI : Semantics-Knowledgeable Interface}

A filosofia deste sistema baseia-se no processo de visão semântica dos dados, isolando dados relacionados e determinando os efeitos de uma atualização centralizada em torno do conceito de uma "session view". Durante a sessão com a interface, o usuário seleciona componentes da interface 
no esquema e examina o esquema para a informação relacionada.

SKI [Kin_84] suporta modelos de dados que são funcionalmente muito similares a conjuntos restritos do modelo semântico SDM.

Em SKI não existe a noção de "lay-out" gráfico definido estaticamente. Ao invés disso, SKI usa o relacionamento semântico herdado na definição do esquema para executar a representação gráfica. A parte da base de dados a ser mostrada e o tipo de relacionamento descrito variam com a área de interesse do usuário.

Esse sistema usa uma tela formatada, um mouse com 3 botões ("DRAG", "SELECT" e "MENU") e alguns operadores semânticos. Os operadores permitem ao usuário examinar e ter acesso à base de dados enquanto utiliza os relacionamentos semânticos herdados do esquema.

O usuário não examina o esquema ao acaso ou navega no grafo de relacionamento. Mais precisamente, ele constrói uma "session view" baseada no significado dos dados e controla diretamente a seleção dos componentes do esquema e a disposição dos ítens na tela. Essa visão consiste de algum subconjunto do esquema e possibilita a criação de novos tipos, atributos, restrições e subtipos.

Enquanto constrói uma "session view", o usuário utiliza uma tela formatada, que pode ser vista na figura 2.10. A tela oferece um meio para representar a estrutura complicada do esquema semântico. A tela é dividida em várias faixas horizontais. A faixa do topo contém um ou mais tipos pai, os quais podem ser qualquer tipo ou subtipo do esquema. A próxima faixa contém os atributos do tipo pai.

Os domínios dos atributos são mostrados na terceira faixa. Predicados baseàdos em qualquer tipo pai são mostrados na próxima faixa abaixo e subtipos dos tipos pais são mostrados na quinta faixa. A sexta faixa (não mostrada na figura) é reservada para atributos do tipo domínio da terceira faixa. Da sétima à nona faixa mostram-se os domínios, predicados e subtipos do tipo domínio da terceira faixa. As faixas continuam dessa maneira. Qualquer faixa de predicado pode referenciar um tipo ou subtipo de uma faixa pai ou de qualquer faixa domínio. 


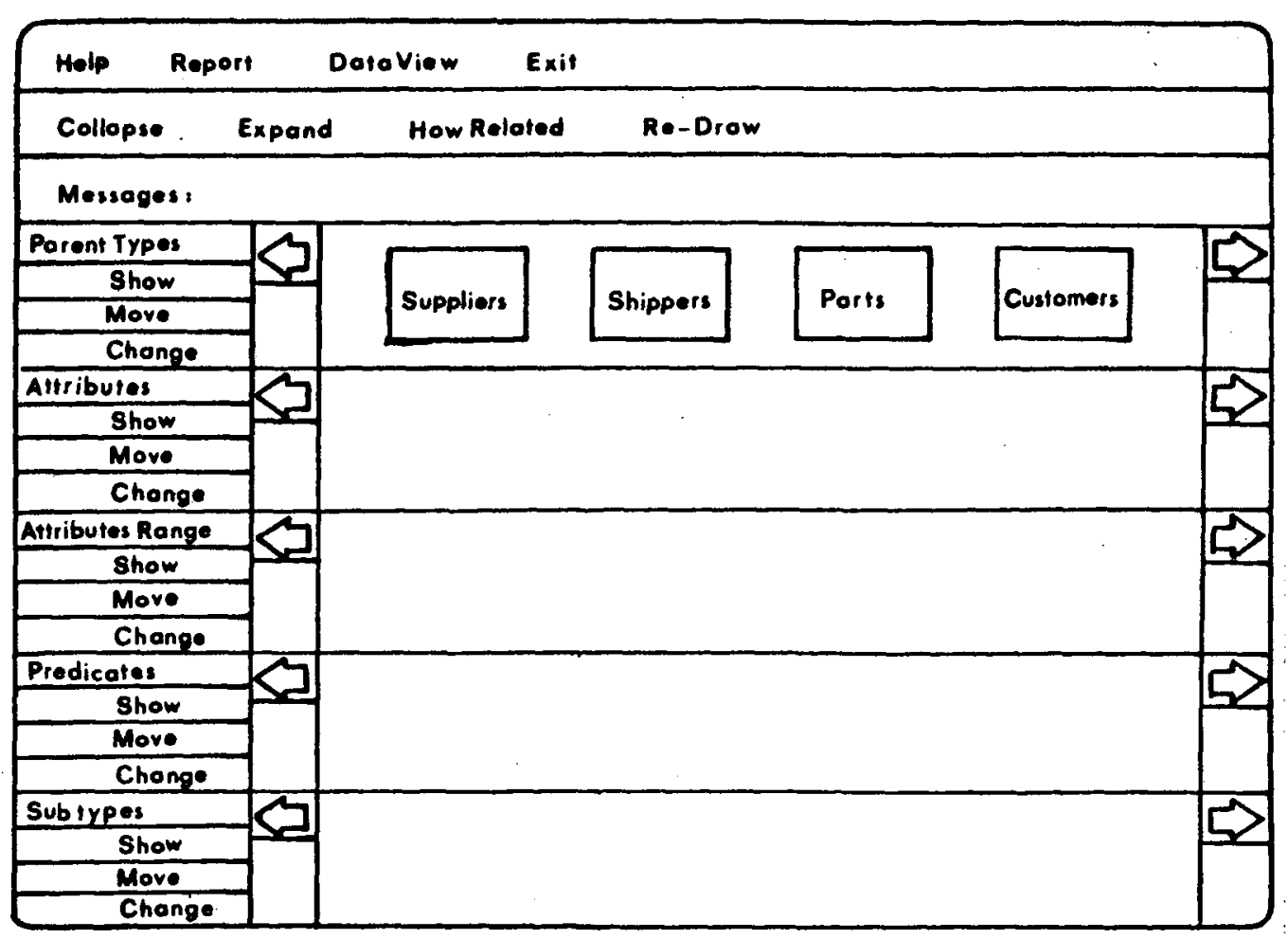

Figura 2.10: SKI: visão geral da interface

Os botões do mouse são usados para controlar as operações de tela , tais como: deslizar, expandir ou contrair faixas, mover imagens na tela, colocar componentes do esquema na tela, etc.

Esse sistema oferece uma maneira baseada em semântica para se requerer informações que estão relacionadas com um dado componente do esquema. Uma das formas utiliza o menu "How Related", oferecido pelo sistema, o qual é usado para mostrar como dois componentes do esquema estão relacionados. Dois componentes do esquema podem estar relacionados via atributos, definição de predicados, ou relacionamentos tipo/subtipo. A seguir, é mostrado um exemplo para o caso acima.

Considere que um usuário tenha escolhido como parâmetros os tipos "suppliers" e "customers" na figura 2.10 e deseje saber como esses componentes estão relacionados. O operador "How Related" mostra em uma tela 


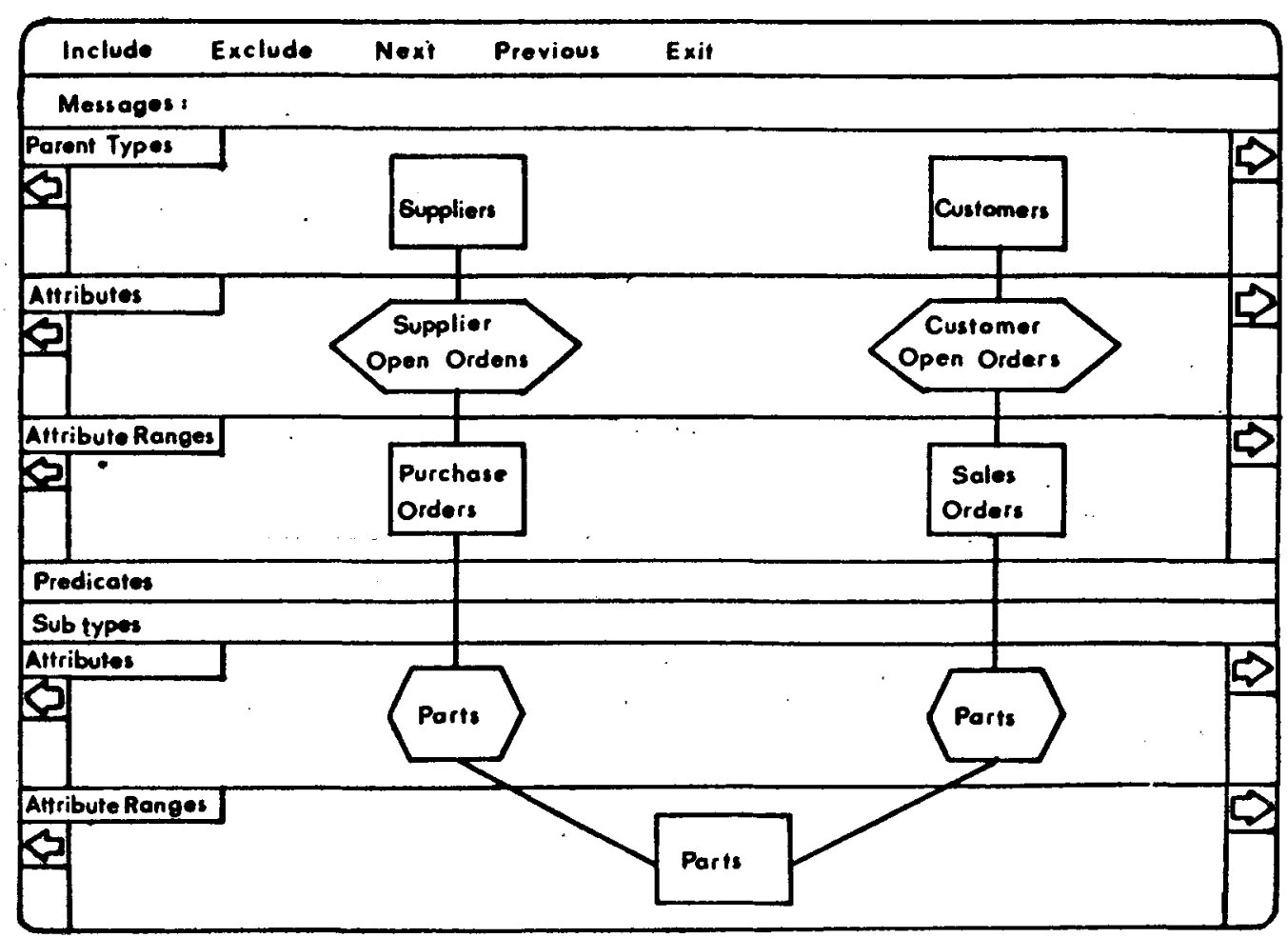

Figura 2.11: SKI: relacionamento entre entidades

separada os dois componentes de interesse. O operador "next" nessa nova tela (figura 2.11) dá o próximo relacionamento entre os dois componentes. Após a verificação do relacionamento entre os dois componentes, o usuário pode incluir esta informação em sua "session view" através da operação "include" oferecida no menu.

Outra maneira de isolar relacionamentos motivados por semântica é com o operador "Show Update Effects". O usuário escolhe a operação e o sistema informa ao usuário quais componentes podem ser afetados se a operação dada for executada. 


\subsubsection{ISIS: Interface for a Semantic Information Sys- tem}

Este sistema utiliza recursos visuais para programação em base de dados. Permite ao usuário construir uma base de dados ou modificá-la, navegar no conteúdo da BD para obter informações sobre os dados ou sobre o esquema, e também formular consultas que podem ser salvas para uso posterior.

ISIS[Gol_85] tem disponível uma interface gráfica para um subconjunto modificado de conceitos do modelo semântico SDM. Esse sistema proporciona visões múltiplas do esquema da base de dados, como também visões dos dados.

Uma visão corresponde a uma tela de uma estação de trabalho. Uma visão deve conter: (i) menus, (ii) janelas de textos, e/ou (iii) janelas. Esses componentes são representados por áreas retangulares disjuntas dentro da visão.

Esse sistema opera com dois níveis: o nivel do esquema e n nível dos dados. $\mathrm{O}$ nível do esquema proporciona visões do plano de esquema. $\mathrm{O}$ nivel dos dados proporciona visões do plano de dados. Em ambos os níveis é possível navegar usando o mapeamento formado pelos atributos no esquema. Os estados de ISIS consistem de uma seleção do esquema e uma seleção dos dados.

Sendo o sistema ISIS baseado no modelo SDM, esse sistema vai permitir ao usuário trabalhar com entidades, onde essas entidades têm atributos associados e as entidades são agrupadas em tipos similares, formando as classes, que é o conceito fundamental de SDM.

As classes são relacionadas umas com as outras através de ligações entre elas. As duas ligações mais comuns são as associações de subclasses e associaçôes de agrupamento. Se houver uma associação de subclasses entre as classes $\mathrm{S}$ e $\mathrm{T}$, diz-se que $\mathrm{T}$ é uma subclasse de $\mathrm{S}$ e também que $\mathrm{S}$ é uma super classe de T. Outra característica importante é que os membros de uma classe herdam os atributos de suas super classes. 


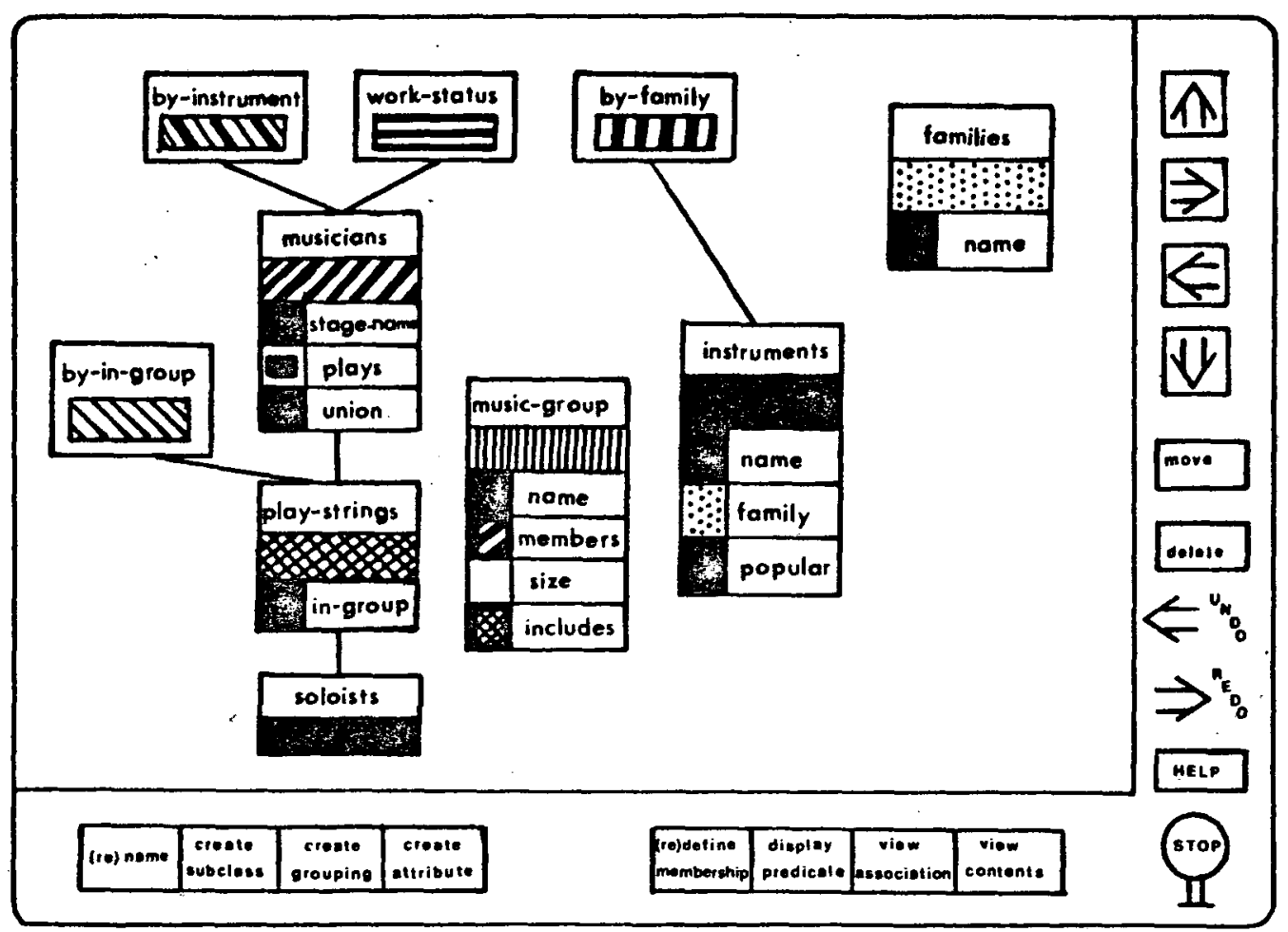

Figura 2.12: ISIS: visão geral da interface

Uma restrição do modelo SDM no modelo ISIS, é que um agrupamento é permitido apenas sobre um valor comum de um atributo. Outra restrição é que foi limitado o comportamento de herança de uma subclasse a uma única super classe.

É importante notar que em ISIS a construção de uma consulta é equivalente a definir uma nova classe derivada. A classe derivada é especificada em termos de predicados que correspondem a expressões de consultas de linguagens mais tradicionais. ISIS permite aos usuários construir os predicados usando meios gráficos.

A seguir é analisado um exemplo utilizando esta interface. É assumido a existência de uma base de dados "Instrumental_Music" que tem como classes básicas "musicians", "instruments", "music-groups" e "families" (ver figura 2.12). 
As classes têm 3 partes: (1) a seção do nome da classe; (2) uma característica de identificação única da classe, que é automaticamente oferecida pelo sistema; (3) uma seção de atributos.

Os atributos da seção de atributos de uma classe possuem os nomes e as características de identificação de suas classes. Se o atributo é multivalorado, sua característica de identificação de classe é mostrada com uma borda branca para indicar que o valor do atributo é um conjunto (por exemplo: o atributo "plays" na classe "musicians" na figura 2.12).

Os agrupamentos são representados da mesma maneira que as classes, mas eles não tem seção de atributos e suas características de identificação de classe tem uma borda branca para indicar que seus membros são conjuntos.

Após carregar a base de dados, o usuário têm a "inheritance forest view" da base de dados (figura 2.12). Pode-se então escolher um objeto sobre o qual se quer focalizar a atenção. Como um exemplo, suponha-se que o usuário tenha interesse no atributo multi-valorado "plays" da classe "musicians" e seleciona a opção para ver a classe "instruments". Assim, a classe "instruments" torna-se um novo esquema selecionado e seu grafo semântico é mostrado na figura 2.13 .

Após ter verificado o grafo semântico, se o usuário decide ver o conteúdo da classe "instruments", ele pode selecionar a opção "pop" para retornar a "inheritance forest", onde "instruments" será selecionada. Com a opção "view contents", oferecidano menu, é mostrado o nível de dados desta classe. É mostrada a classe "instruments" com todos seus atributos e uma lista de suas entidades membros. Usando "select/reject", o usuário pode escolher membros sobre quais focalizar sua atenção; os membros selecionados são destacados em negrito. Na figura 2.14 já tem-se selecionado "flute" e está sendo selecionada a entidade "oboe". Quando o usuário quer encerrar sua consulta é oferecida a opção "stop" (ver canto inferior direito da figura 2.12).

O sistema oferece muitas operações ao usuário para que possa navegar na base de dados, entre elas, pode-se citar que é possivel modificar os dados para corrigir erros, pode-se acrescentar informações ao esquema através da formulação de consultas e assim, são criadas novas sub-classes e 


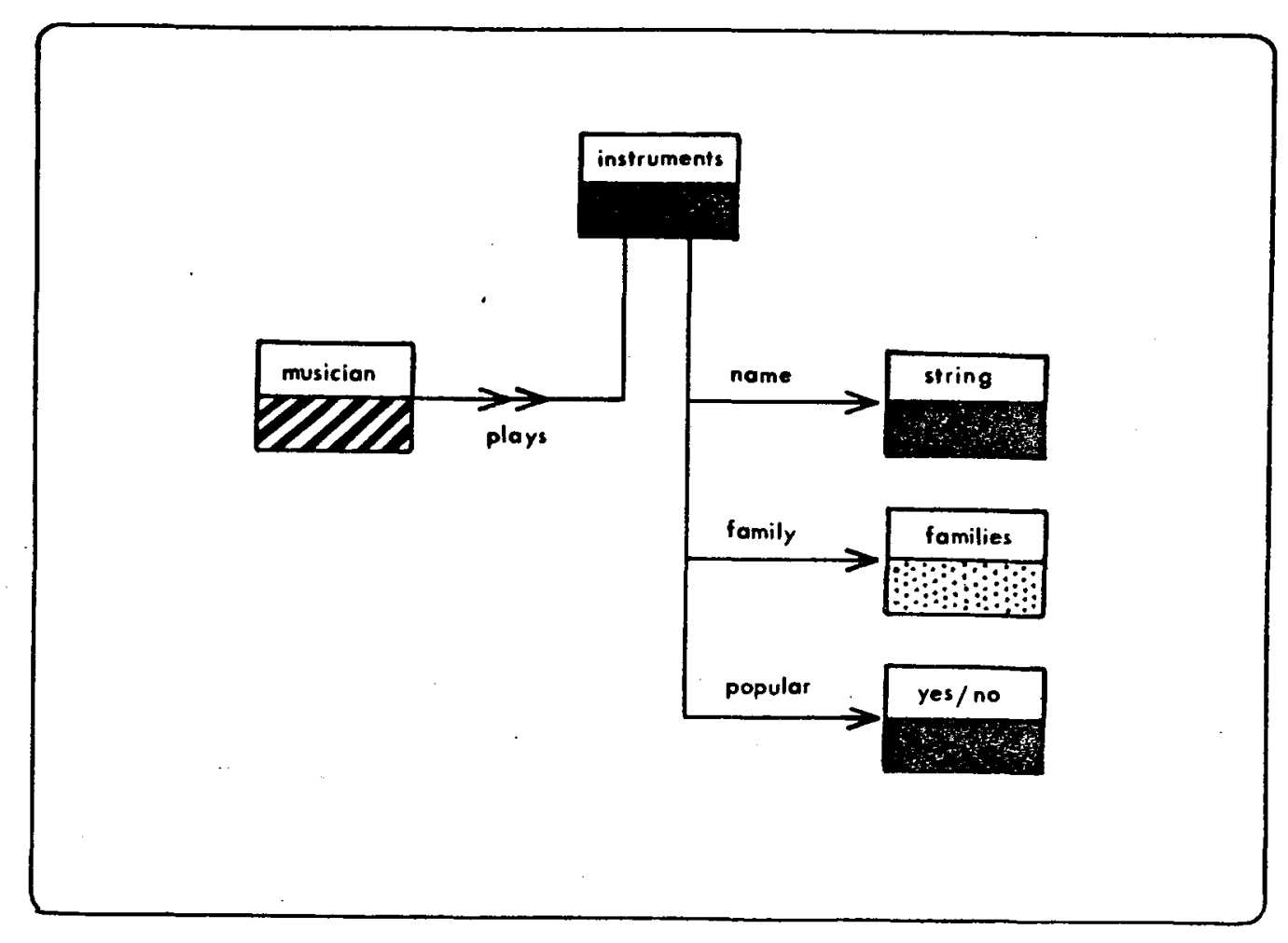

Figura 2.13: ISIS: seleção de uma classe

podem-se acrescentar atributos a essas sub-classes.

\subsection{Avaliação Comparativa dos Browsers Re- visados}

É apresentada na figura 2.15 uma síntese dos browsers que foram revisados para a dissertação de mestrado. A tabela apresenta o modelo de dados em que foi baseado o sistema e compara esses sistemas fazendo uma separação:em duas áreas: funcionalidade e extensões para as quais os gráficos são usados.

Conforme a funcionalidade apresentada na tabela, tem-se que 


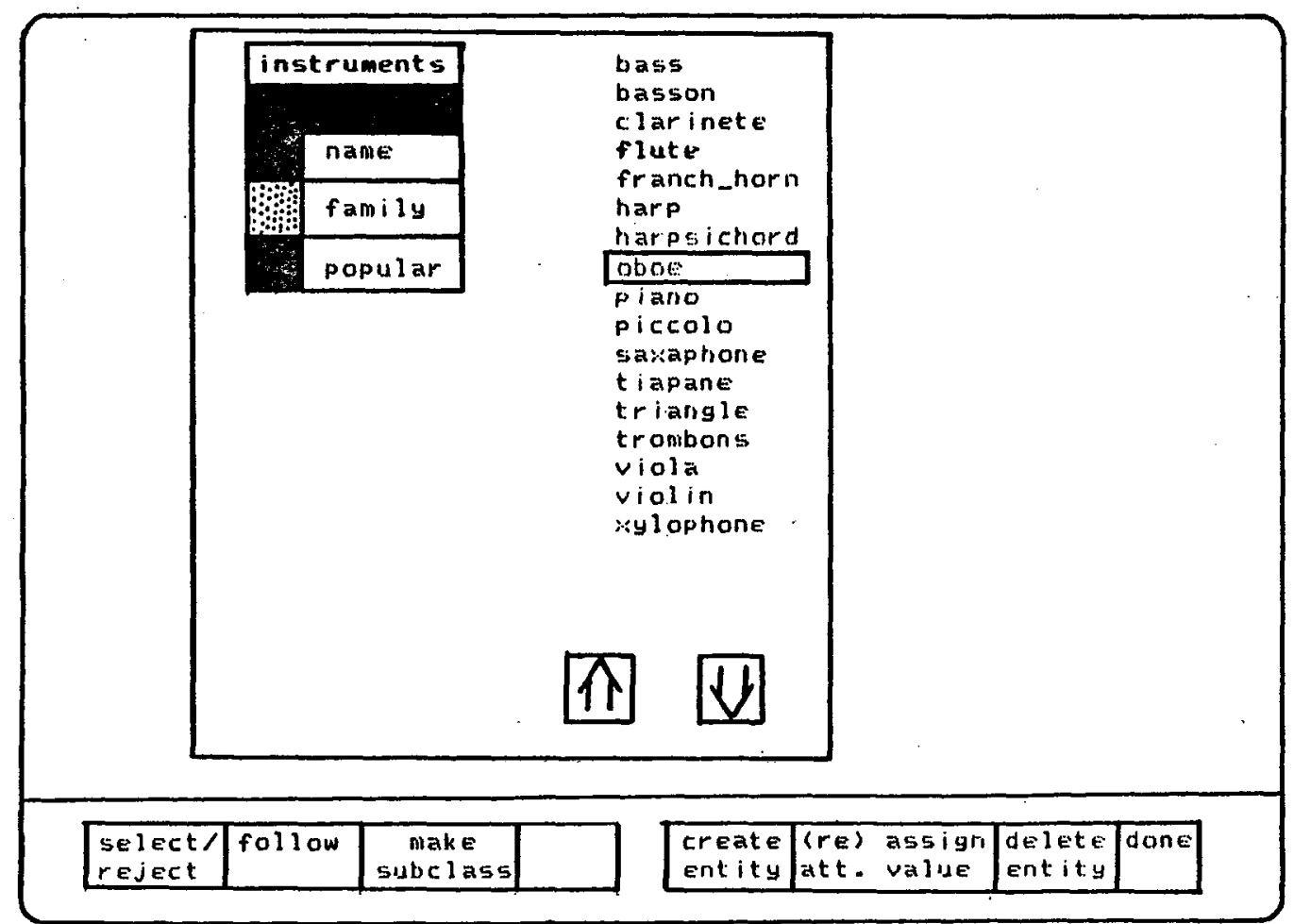

Figura 2.14: ISIS: uma classe com atributos e suas instâncias

dos sistemas pesquisados apenas o sistema LID não se concentra no gerenciamento do esquema, oferecendo recursos para definição ou navegação no esquema e formulação de consulta.

Uma restrição do sistema LID em relação aos demais é que ele é orientado a consulta de dados, permitindo ao usuário a partir de um objeto específico da base de dados, percorrer o r relacionamentos do esquema para encontrar objetos que estão relacionados a ele. Outra restrição do sistema LID é que ele não oferece recursos para a visão de um conjunto de objetos, apenas objetos individuais.

A segunda área de interesse apresentada na tabela é a utilização de gráficos nos sistemas. Conforme mostra a tabela, os quatro sistemas utilizam estruturas gráficas para representar o esquema, sendo que o sistema LID não oferece uma visão geral do esquema, mas apenas para um item de 
dado individual de cada vez. No sistema GUIDE o esquema é representado pelo diagrama do modelo Entidade-Relacionamento, sendo este uma estrutura estática que não pode ser alterada pelo usuário.

O sistema SKI controla a estrutura visual do esquema para o usuário, enquanto que no sistema ISIS o usuário define diretamente a representação visual do esquema.

Considerando o modo como o usuário navega na esquema enquanto faz uma consulta, todos os sistema, exceto o sistema LID, oferecem mecanismos para tratar diretamente com a representação visual e focalizar em áreas de interesse dentro do esquema.

\subsection{Considerações Finais}

Foram apresentadas neste capitulo as caracteristicas principais dos modelos de dados utilizados nas implementações dos SGBDs. Pode-se concluir que os modelos de dados de um SGBD convencional, orientado a registro, não são adequados para lidar com aplicações não convencionais, o que levou à criação de novos modelos para a representacão dos dados com um conteúdo semântico maior.

Apresentaram-se algumas interfaces gráficas para base de dados baseadas em modelos semânticos onde estes modelos permitem representar dados com conteúdo semântico maior e com uma representação visual mais adequada para ser mostrada graficamente. Observa-se que alguns modelos semânticos já apresentam a Linguagem de Descrição dos Dados (DDL) de uma forma gráfica.

O desenvolvimento de interfaces gráficas foi impulsionado pelo advento da tecnologia em Estação de Tabalho, pois permitiu o desenvolvimento de equipamentos com preços mais baixos e oferecendo recursos fundamentais para a computação gráfica, tais como: telas do tipo bit-mapped, dispositivos apontadores para seleção (como o mouse) e sistemas eficientes para gerenciamento de janelas. 


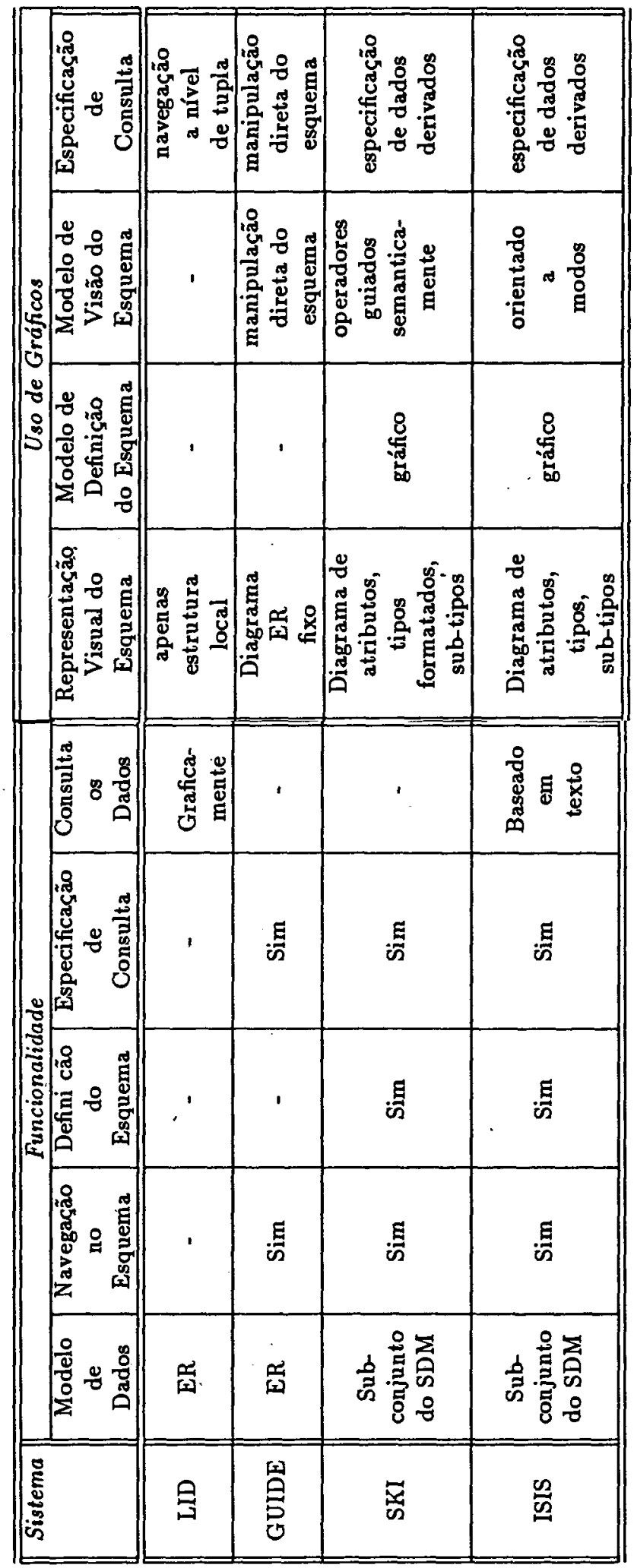

Figura 2.15: Tabela de comparação dos browsers 


\section{Capítulo 3}

\section{Um "Browser" para o SGBD Damokles}

\subsection{Considerações Iniciais}

Neste capitulo descreve-se a implementação de um browser para o SGBD Damokles. As características principais do sistema são descritas, bem como as principais decisões de projeto.

$\mathrm{Na}$ seção 3.2 é apresentado o modelo de Dados DODM do SGBD Damokles. A seção seguinte, 3.3 , é dedicada à apresentação do modelo de dados utilizado na implementação do browser desenvolvido. Na seção 3.4 é apresentada a arquitetura geral do sistema, descrevendo-se os seus módulos e os dois níveis utilizados para consultar o esquema da base de dados. Complementa-se o capítulo apresentando-se na seção 3.5 alguns dados quantitaivos sobre a implementação realizada. 


\subsection{O Modelo de Dados do SGBD Damokles}

O sistema DAMOKLES (DAtabase Management system Of KarLsruhe for Environments for Software engineering) é um SGBD para Engenharia de Software desenvolvido pela Universidade de Karlsruhe, Alemanha. Foi projetado e implementado para superar as dificuldades experimentadas pelos produtos de bancos de dados atualmente disponíveis, quando aplicados a ambientes de projeto [Pim_89].

O objetivo do Damokles é oferecer os recursos necessários ao suporte a ambientes de engenharia de software de modo a obter um desempenho aceitável. Para isto, Damokles inclui novos enfoques de tecnologia de $\mathrm{BD}$, que são direcionados especificamente a ambientes de engenharia de software.

Damokles é parte do projeto alemão UNIBASE, cuja finalidade é produzir um ambiente de engenharia de software e esse sistema será usado como o repositório básico dos dados (provavelmente distribuído em uma rede de estações e servidores), integrando as várias ferramentas que suportam as diversas fases do ciclo de vida de um um sistema através da interface de banco de dados comum.

O modelo de dados do Damokles, o DODM(Design Object Data Model), é um modelo de dados dedicado a expressar a semântica de Ambientes de Desenvolvimento de Software (ADS). Sua definição foi guiada por três linhas básicas:

- generalidade (permitindo ADS arbitrários, evitando um SGBD dedicado para cada ADS);

- simplicidade (possuindo poucos conceitos);

- funcionalidade (propiciando implementação eficiente).

O DODM é baseado no modelo Entidade-Relacionamento. Possui conceitos de modelagem que permitem representar uma entidade do 
mundo real por apenas um objeto do BD independente de sua complexidade ou estrutura interna. Para apoiar melhor a orientação a objetos, os conceitos básicos do modelo ER foram estendidos com objetos estruturados e versões de objetos.

As estruturas básicas do DODM são:

- objetos estruturados (complexos) com versões;

- relacionamentos entre objetos e/ou versões;

- atributos para objetos/relacionamentos.

O DODM possui uma linguagem DDL(Data Definition Language) [Abr_87a] para a descrição do esquema. O esquema DODM consiste de um conjunto de declarações de tipos de objetos (OBJECT TYPES), tipos de relacionamentos (RELSHIP TYPE), conjuntos de valores (VALUE_SETS) e constantes (CONST). Para tornar o esquema conhecido ao SGBD, sua descrição deve ser submetida ao compilador da DDL, que analisa o esquema e armazena sua representação no dicionário de dados.

O conjunto de valores descreve os domínios dos atributos dos tipos de objetos ou relacionamento. Qualquer conjunto de valores deve ser definido antes de ser usado.

Os conjuntos de valores pré-definidos são: CHAR, INT, BOOL, TIME (dia, mês, ano, hora, minuto, segundos) e LONG_FIELDS. Camposlongos (LONG_FIELDS) são sequências de caracteres de tamanho variável, usadas para representar o conteúdo de documentos, sem tornar conhecida ao SGBD sua estrutura interna.

Para a combinação de conjuntos de valores, existem os construtores de tipos: enumeração (ENUM), vetores (ARRAY), vetores de CHAR (STRING), intervalos (SUBRANGE), estruturas (STRUCT) e união (UNI$\mathrm{ON})$, todos similares aos construtores da linguagem $\mathrm{C}$.

Um objeto DODM é composto de uma parte descritiva e uma parte estrutural. 
A parte descritiva é composta de atributos. Um ou mais atributos formam a chave do objeto, identificando-o unicamente dentro do conjunto de objetos do mesmo tipo no banco de dados. Além disto, o sistema atribui automaticamente um Indentificador de Objeto Único (OID) ao objeto no momento de sua criação.

A parte estrutural inclui um conjunto de sub-objetos e um conjunto de relacionamentos implícitos à estruturação de objetos em hierarquias, denominados relacionamentos de composição. Os sub-objetos, por sua vez, são também definidos como objetos (tipos de objetos) no esquema.

Os objetos do DODM podem possuir diferentes versões. Cada versão pertence a somente um objeto, o objeto genérico.

A característica principal das versões é que sua existência depende da existência de um objeto genérico e que elas envolvem-se em um relacionamento implícito com outras versões do mesmo objeto genérico. Este relacionamento define uma ordem parcial, chamada grafo de versões, sobre o conjunto de versões do mesmo modelo genérico. Versões são numeradas na sequência de criação, que é o critério de ordenação. Uma relação de versões predecessora-sucessora é evidenciaaa no grafo de versões, que pode ser linear, em árvore ou acíclico:

LINEAR - cada versão tem no máximo um sucessor e um predecessor;

ÁRVORE - cada versão tem um número arbitrário de sucessores mas exatamente um predecessor;

ACÍCLICO - cada versão tem um número arbitrário de sucessores e predecessores.

Os relacionamentos no modelo DODM são associações n-árias bidirecionais de objetos. Cada objeto envolvido no relacionamento possui um papel. Para cada papel pode ser especificada uma cardinalidade mínima ou máxima de tipos de objetos participantes naquele papel. Quando não especificada, é assumida a cardinalidade 1 como mínima e máxima.

O DODM possui algumas restrições de integridade inerentes ao modelo, entre as quais: 
- unicidade das chaves primárias definidas pelo usuário;

- integridade referencial para relacionamentos, isto é, um relacionamento pode ser automaticamente removido se um dos objetos com o qual está relacionado é removido;

- Cardinalidade dos papéis nos relacionamentos, isto é, o usuário pode especificar para cada papel num relacionamento uma cardinalidade mínima e máxima, que define se um objeto deve participar (AT LEAST ONCE) ou se pode participar (AT MOST ONCE) de um papel de um determinado tipo de relacionamento.

Além das restrições implícitas, um mecanismo especial para restrições explícitas, específicas para cada aplicação, foi projetado para que o usuário possa definir seu controle de consistência complexo. O SGBD, com estas definições, pode verificar a consistência e reagir a violações das restrições apropriadamente. $\mathrm{O}$ mecanismo especial proposto para o Damokles é o mecanismo de evento/gatilho (Event/Trigger Mechanism).

O Damokles possui uma Linguagem de Manipulação de Dados (DML) [Abr-87b] que consiste de um conjunto de operações genéricas as quais podem ser usadas para recuperar, manipular e atualizar os dados armazenados no BD́ Damokles. Os operadores da DML devem ser embutidos em programas na linguagem $\mathrm{C}$, escolhida porque o ambiente do Damokles é o UNIX. É caracterizada como uma linguagem navegacional, isto é, que trata um objeto de cada vez. $\mathrm{O}$ programa de aplicação pode ter acesso e manipular os dados armazenados navegando de objeto a objeto via os relacionamentos (explícitos ou de composição) entre eles.

O Damokles distingue entre transações curtas e transações longas. Dentro do Damokles, uma transação curta é a unidade de consistência, sincronização e restauração. $\mathrm{O}$ aninhamento de transações não é permitido, isto é, uma transação ativa deve ser terminada antes de outra ser iniciada. Após o término correto (normal) de uma transação curta, todas as alterações realizadas desde que a transação iniciou são tornadas permanentes na BD. Entretanto, se violações de restrições de integridade forem detectadas, a transação será interrompida, desfazendo todas as suas alterações. 
O usuário do Damokles tem a possibilidade de requisitar objetos dos BD públicos para seus BD privados, a fim de trabalhar sobre estes objetos por um longo periodo de tempo. Esta necessidade, que é típica para aplicações de BD para ambientes de projeto, é comumente chamado de transação longa.

Embora a DML-Damokles seja uma interface do tipo "um objeto por vez", existem situações em que é necessário lidar com conjuntos de objetos com propriedades comuns. Um exemplo é uma pesquisa associativa, recuperando um conjunto de objetos ou relacionamentos que satisfazem um critério condicional. Para esta gerência de conjuntos, a DML-Damokles possui o conceito de cursores. Um cursor coleta um conjunto de objetos e/ou relacionamentos do $\mathrm{BD}$ (representados por seus identificadores de objeto único) e os retém temporariamente como uma unidade para um programa de aplicação. $O$ conjunto de objetos é definido por uma expressão de pesquisa.

Além do modelo de dados DODM, o sistema Damokles possui algumas características voltadas a aplicações de projeto, entre as quais mecanismos especiais de segurança, uma arquitetura multinivel e a possibilidade de definir múltiplos BDs.

No apêndice A é apresentado um exemplo de uma DDL associada a um esquema que vai ser analisado pelo browser, esse exemplo é apresentado no próximo capítulo.

No SGBD Damokles tem-se um compilador associado à DDL. Este compilador gera um arquivo contendo o mapeamento do esquema da base de dados para estruturas da linguagem C. Esse arquivo é necessário para a utilização das funçôes DML. Outra importante função do compilador associado à DDL é armazenar as informações do esquema no Dicionário de Dados (Meta Base de Dados).

Na figura 3.1 é apresentado um diagrama em DODM para a modelagem do esquema apresentado no apêndice $A$. 


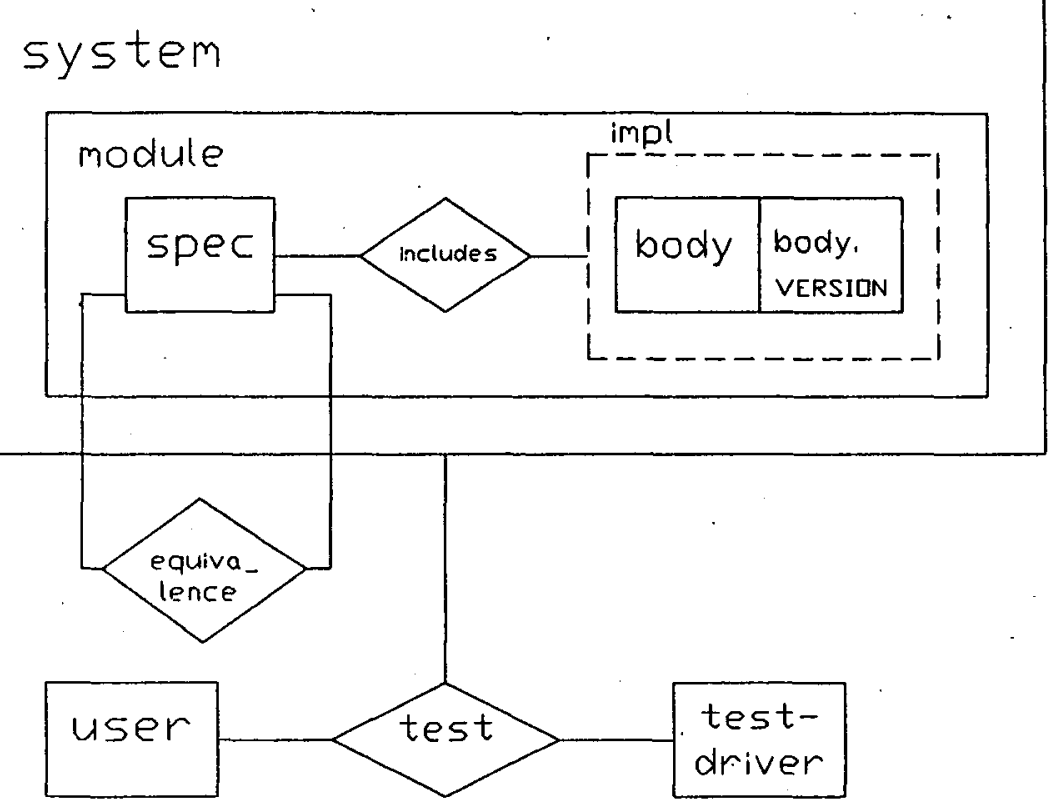

Figura 3.1: Exemplo modelado em DODM

\subsection{O Modelo de Dados Usado no Browser}

O modelo de dados subjacente ao browser é o modelo DODM (Design Object Data Model) desenvolvido para o sistema de Gerenciamento de Base de Dados Damokles acrescentando-se um diagrama para a representação gráfica para este modelo, proposto em Hara[Har_90], com o objetivo de facilitar a visualização dos objetos do modelo, principalmente os objetos compostos.

A representação gráfica proposta por Hara[Har_90] está organizada em dois níveis de abstração: um mais genérico, contendo as entidades e seus relacionamentos e outro mais detalhado, para cada entidade, apresentando seus atributos e outros detalhes não representados no nível mais abstrato. 
Para o nível genérico adotou-se a forma de diagramação do modelo entidade-relacionamento, pois é uma representação de fácil entendimento e largamente difundida. Foi utilizada a notação gráfica de diversas extensões já realizadas ao modelo entidade-relacionamento, algumas delas criadas ou aproveitadas de propostas para outras áreas de conhecimento, como a inteligência artificial. Assim, uma entidade é representada por um retângulo e os relacionamentos são arcos ligando as entidades envolvidas e identificados pelos seus nomes. É utilizado o símbolo de uma "seta" para indicar a cardinalidade do relacionamento: se o arco possui uma seta simples nos dois extremos, tem-se um relacionamento do tipo 1:1. Caso possua um extremo com uma seta dupla, tem-se representado um relacionamento tipo 1:n. Outro símbolo utilizado nesta representação é o simbolo de uma barra (-) para representar um relacionamento parcial, esta barra é desenhada junto com as setas que indicam a cardinalidade do relacionamento e seu significado é que a entidade pode ou não participar do relacionamento.

O objetivo principal da proposta foi enfatizar a parte estrutural dos dados, incorporando mais semântica para representação dos objetos compostos (composição e alternativa de classe).

Composição é um meio através do qual um conjunto de objetos é considerado como parte de um objeto de nível mais alto. Este relacionamento é comumente chamado de IS-PART-OF e é a essência do modelo DODM do Damokles. Uma notação especial para este tipo de associação é importante para que as estruturas dos objetos sejam destacadas. Convencionou-se representá-la com um arco mais espesso que a dos demais relacionamentos, partindo do objeto de nível mais alto para os de nível mais baixo. É usada também a notação de dupla seta para relacionamentos tipo 1:n e de uma barra para relacionamentos parciais.

Para representar tanto composições como alternativas de classe, que correspondem às clausulas STRUCTURE e UNION da DDL Damokles, aproveitou-se a notação dos grafos AND/OR, utilizados essencialmente para representar decomposições de problemas na área de inteligência artificial. Assim, um objeto composto por dois sub-objetos é representado pela notação AND, que consiste de um circulo desenhado sob os arcos que partem do objeto de mais alto nivel. As alternativas de classe são representadas pela notação OR, identificadas simplesmente pela ausência do círculo. 


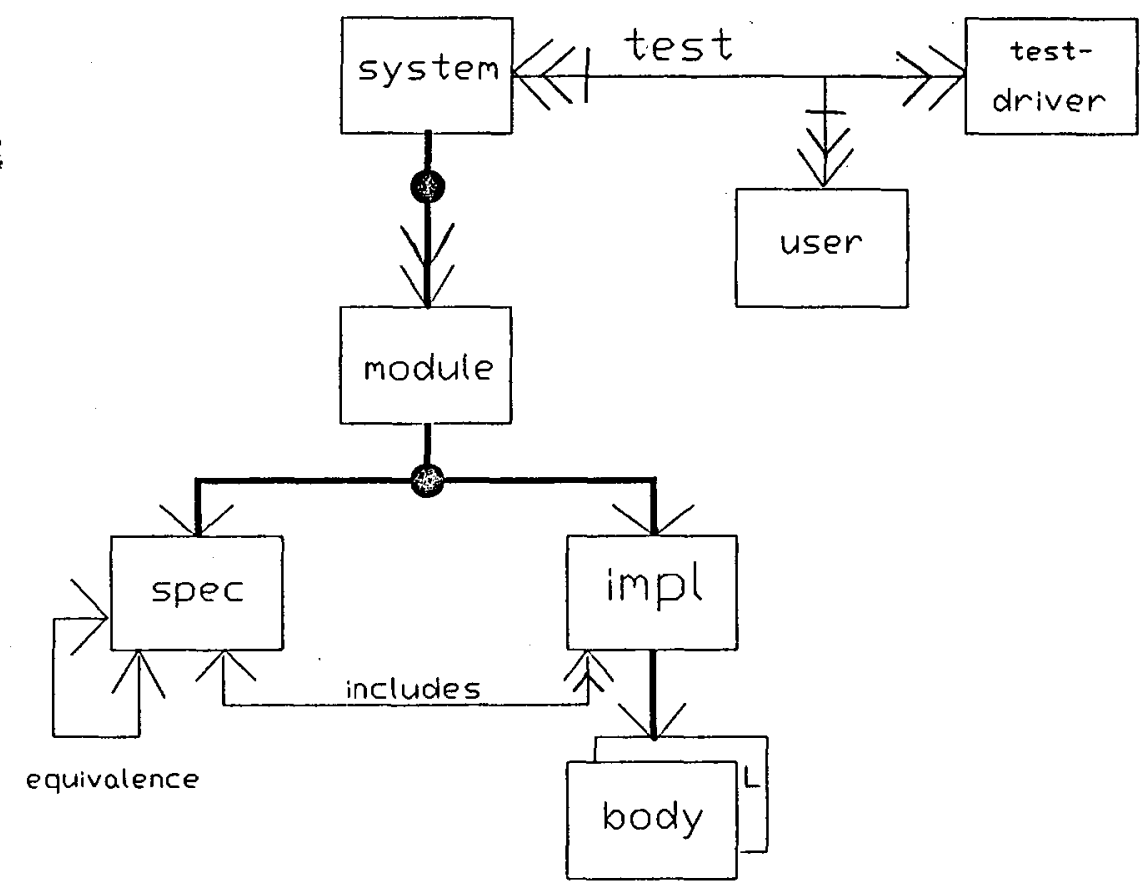

Figura 3.2: Exemplo modelado segundo as notações de Hara

Tem-se na figura 3.2 o diagrama associado ao esquema do apêndice A, segundo a notação apresentada em [Har_90].

O nivel detalhado utilizado no diagrama para a representação gráfica para o modelo DODM foi desenvolvido com o propósito de não sobrecarregar o nível genérico, tornando-o mais claro e conciso. Assim, para cada entidade do nível genérico é apresentada uma nova representação no nível detalhado onde os atributos e relações são explicitamente definidos para a entidade genérica e para suas versões, caso ela as possua.

De forma coerente com a notação de relacionamentos usada no nível genérico, a multivaloração de atributos é representada por uma flecha dupla, sendo que uma barra indica que o atributo é opcional. Nota-se que, enquanto no modelo genérico os relacionamentos de uma entidade envolvem indistintamente o objeto genérico ou suas versões, no modelo detalhado estes 
são explicitamente definidos. Este modelo não segue o conceito tradicional, onde as versões possuem as mesmas propriedades que o objeto genérico. Além disso, é possível declarar atributos diferenciados às versões, como por exemplo: um atributo data de criação, típico para um objeto versão. Esta notação pode ainda assumir a semântica de que os atributos da entidade genérica são aqueles que não variam ou que não são de interesse para que se guardem versões.

O browser implementado está organizado em dois níveis, o nivel geral e o nível de instância. A seguir será discutido cada um desses níveis.

No nível geral do browser foi utilizado o diagrama para representação do modelo DODM apresentado no nível genérico do trabalho desenvolvido por Hara[Har_90]. Algumas alterações de pequena importância foram introduzidas no modelo de Hara para facilitar a implementação do browser:

- Para simplificar o acesso a um objeto do tipo relacionamento num esquema de uma base de dados foi criado um símbolo para os relacionamentos. Este sín.uulo é um círculo e está localizado no arco que representa o relacionamento.

- Por motivo de simplificação não será apresentado no nível geral' do browser o nome do relacionamento. Caso o usuário deseje saber o nome de um relacionamento que está sendo apresentado na tela, é preciso pressionar o botão direito do mouse sobre o círculo que representa o relacionamento e então será exibido um menu contendo opções para o objeto relacionamento. Entre as opções é oferecida uma para obter o nome do relacionamento selecionado.

É apresentado na figura 3.3 um diagrama mostrando a notação a ser utilizada no nível geral do browser, este diagrama corresponde ao esquema cuja DDL é apresentada no apêndice $\mathrm{A}$ e corresponde também à figura 3.2 com pequenas alterações realizadas para a implementação do browser. No próximo capítulo, na seção 4.3 , é apresentado um exemplo de uma sessão do browser; isto facilitará o seu entendimento. 


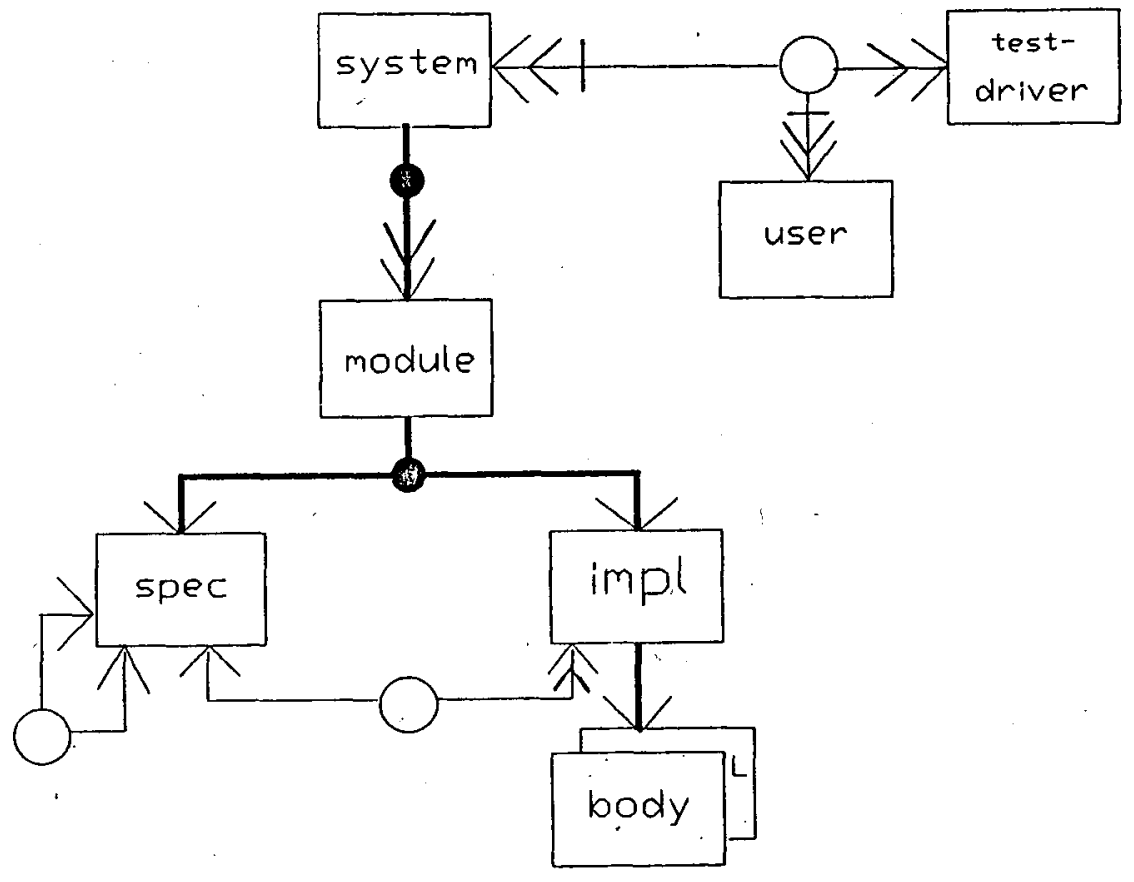

Figura 3.3: Exemplo modelado segundo as notações do browser

O segundo nível usado no browser é o nível de instâncias. Este nivel é usado para se ter acesso ao conteúdo das instâncias que estão armazenadas na base de dados. Uma chamada para esse nivel é feita através da escolha de um item de menu ("instâncias") que é oferecida no menu de entidades ou no menu de relacionamentos do esquema.

Para o nível de instância é criada uma janela sobreposta à janela do nivel geral e nessa janela são mostrados os nomes dos atributos e seus conteúdos. Caso o número de instâncias armazenados na $\mathrm{BD}$ não caiba na tela, esta disponível a opção de "scroll" ao usuário para que ele possa ter acesso a todas as instâncias desejadas. Para o retorno à janela de nível geral é oferecida essa opção no menu da janela de instância. 


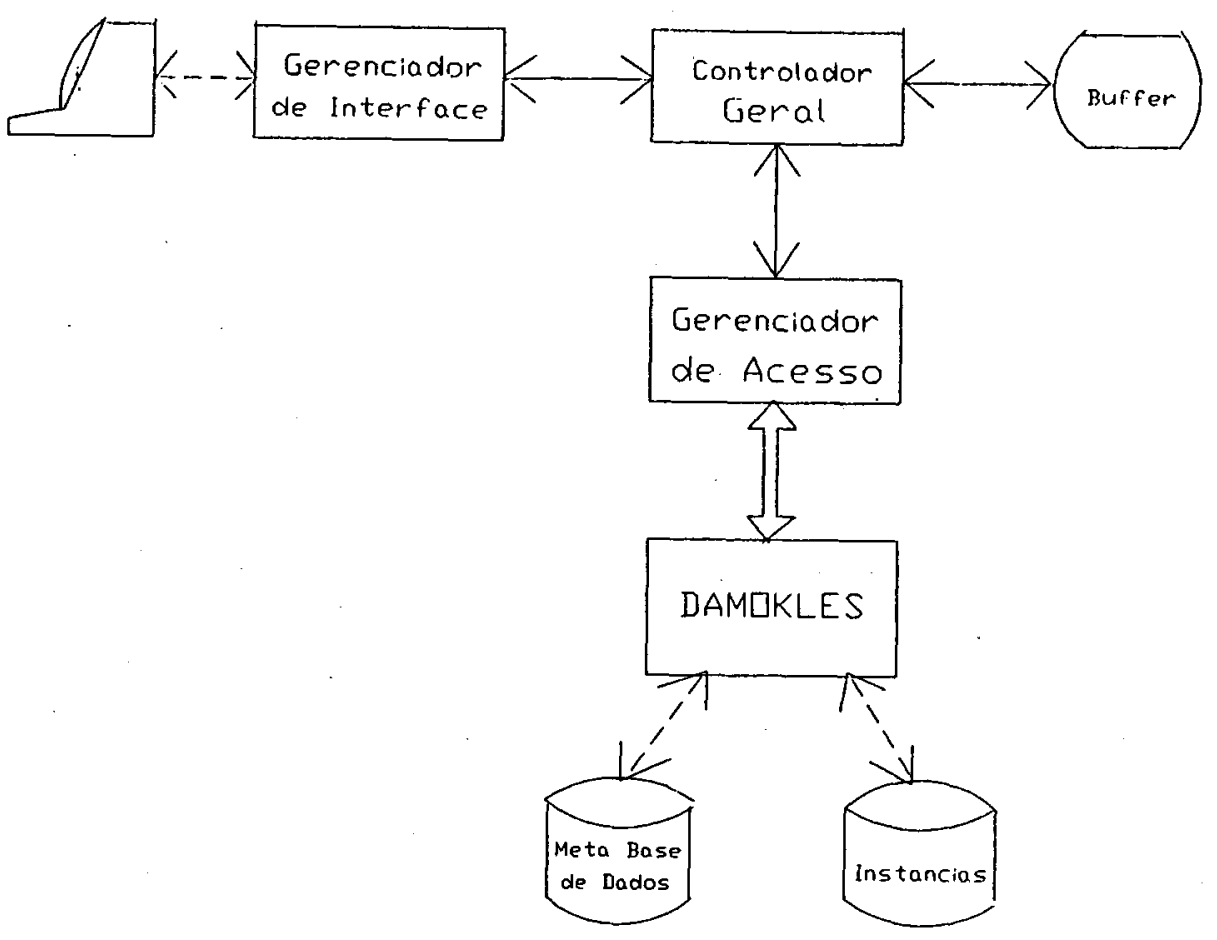

Figura 3.4: Arquitetura Geral do Sistema

\subsection{Arquitetura Geral do Sistema}

Descrēve-se nesta seção a arquitetura geral utilizada no desenvolvimento do browser. 0 sistema implementado é composto por 3 módulos: Gerenciador de Interface, Controlador Geral e Gerenciador de Acesso. Apresenta-se na figura 3.4 em forma diagramática a estrutura do sistema.

O Módulo Gerenciador de Interface controla todas as rotinas referentes à interface com o usuário, recebendo suas entradas através de informações transmitidas via teclado ou mouse e apresentando no monitor as ações correspondentes. Neste módulo foram utilizados recursos do Sistema de Gerenciamento de Janelas Sunview para a contrução das janelas do sistema e fazer o gerenciamento das informações sobre elas. Foram utilizadas do Sunview funções que criam o mapa de pixel para as janelas onde é mostrado 
o diagrama correspondente ao esquema da BD. Também, são utilizados recursos para a criação de menus, que é o meio de interação fundamental em um sistema do tipo do Browser.

No desenvolvimento do módulo Gerenciador de Interface foi utilizado um pacote gráfico SunCGI[SCG_88] para fazer os desenhos dos objetos que compõem o diagrama que representa o esquema. A utilização desse pacote gráfico foi necessária, pois o sistema SunView não oferece primitivas para o desenho de círculos, que foi usado para representar relacionamentos no diagrama do esquema da base de dados.

Outro módulo utilizado é o Controlador Geral. Esse módulo coordena as chamadas a outros módulos, sendo o elo principal na interação do usuário com a base de dados, através da chamada de sub-rotinas desenvolvidas pelo módulo Gerenciador de Acesso.

É no módulo Controlador Geral que se analisa o arquivo de entrada de dados para o sistema. Este arquivo é utilizado para montar o diagrama correspondente à DDL do esquema a ser analisado pelo browser. $O$ arquivo de entrada é composto pelo nome das entidades e dos relacionamentos do esquema, além de alguns pontos que são utilizados para o desenho dos arcos que representam um relacionamento. $O$ arquivo de entrada é interpretado pelo Controlador Geral, que reconhece os itens léxicos do texto de entrada e se a sintaxe da linguagem que reconhece este arquivo estiver correta, é montada uma estrutura em memória real com informações sobre cada objeto. No apêndice B é apresentado o arquivo de entrada do exemplo a ser analisado via browser.

O módulo Controlador Geral interage com o Módulo Gerenciador de Acesso durante a montagem das estruturas que são mantidas no buffer. Como exemplo dessa interação, tem-se rotinas para certificar que todos os elementos da estrutura estão realmente armazenados na base de dados e também rotinas para verificar se todos os elementos, do esquema que está sendo analisado, foram carregados na memória; caso as condições desejadas não forem satisfeitas, será impressa uma mensagem indicando qual elemento não está satisfazendo a condição e a execução do browser será interrompida.

Outro exemplo da interação entre os módulos Controlador Geral 
e Gerenciador de Acesso pode se visto quando deseja-se saber os nomes dos atributos de uma entidade ou relacionamento do esquema. Estas informações são mantidas pelo meta esquema e foi implementada uma rotina para executar esta operação no Módulo Gerenciador de Acesso.

O Módulo Gerenciador de Acesso é composto por um conjunto de rotinas que necessitam de alguma informação armazenada na base de dados. Estas informações podem se referir às instâncias da base de dados do usuário ou podem ser informações sobre o esquema, que são mantidas na meta base de dados. Este módulo utiliza operadores da Linguagem de Manipulação de Dados (DML) do SGBD Damokles para ter acesso à base de dados. Entre as rotinas desenvolvidas por este módulo tem-se rotinas para carregar o esquema a ser analisado, rotinas para ler informações sobre as instâncias dos objetos do esquema e rotinas para ler os nomes dos atributos de um objeto.

\subsection{Dados Sobre a Implementação Realizada}

O protótipo implementado para a dissertação de mestrado foi desenvolvido numa workstation Sun utilizando-se a linguagem de programação $\mathrm{C}$ com o sistema operacional UNIX. O volume de código do protótipo esta em torno de 7.000 linhas.

Para construir na tela o diagrama correspondente a descrição do esquema de uma base de dados é utilizado um arquivo, referenciado como arquivo de entrada, cujo nome é fornecido pelo usuário no início da sessão com o browser, no mesmo instante em que é fornecido o nome da base de dados que vai ser analisada.

Para interpretar o arquivo de entrada é utilizado um mini analisador léxido que reconhece alguns ítens; entre esses ítens tem-se o tipo do objeto, que pode ser uma ENTIDADE, um RELACIONAMENTO ou um OBJETO_COMPOSTO. Após reconhecer o tipo de um objeto, tem-se um número indicando o número de objetos daquele tipo e esses objetos são apresentados nas linhas posteriores. Um exemplo de um arquivo de entrada é apresentado no apeêndice $B$. 
$\mathrm{Na}$ implementação do protótipo para o browser foi utilizado o Sistema de Gerenciamento de Janelas SunView[SVi_88] (Sun Visual/Integrated Environment for Workstations) para dar apoio à interface. Este sistema é um conjunto de ferramentas para interface com o usuário e dá apoio a aplicações interativas e gráficas que estão sendo executadas em janelas. Sua funcionalidade pode ser separada em duas áreas, uma para a construção de blocos para a saída e a outra área para o gerenciamento das entradas para o sistema.

$\mathrm{Na}$ interface implementada as informações são apresentadas em janelas e como estas janelas são implementadas utilizando o sistema SunView, tem-se facilidades para o seu gerenciamento. Como exemplo dessas facilidades tem-se que $o$ usuário pode redimensionar as janelas, mudar a sua localização e gerenciar a sobreposição das janelas, além de opções para realizar "scroll" no conteúdo da janela.

Para o desenho dos círculos utilizados no diagrama do esquema da base de dados foi utilizado o pacate gráfico SunCGI que é um conjunto de primitivas básicas para desenho geométrico. Este pacote foi necessário pois o SunView não oferece primitivas para o desenho de um círculo.

\subsection{Considerações Finais}

Foi apresentado neste capítulo um browser para o SGBD Damokles. Apresentou-se o modelo de dados do SGBD Damokles e uma diagramação para este modelo que foi utilizada pelo browser implementado. Esta diagramação tem como objetivo facilitar ao usuário a identificação dos objetos do esquema e também os relacionamentos entre esses objetos.

A arquitetura geral utilizada no desenvolvimento do sistema também foi apresentada e, assim, tem-se uma idéia da interação entre os módulos do sistema. No próximo capítulo apresenta-se com mais detalhes os aspectos funcionais implementados. 


\section{Capítulo 4}

\section{Detalhes da Implementação Realizada}

\subsection{Considerações Iniciais}

Neste capítulo é apresentada uma sessão de uso do browser desenvolvido para o SGBD Damokles. O objetivo é dar ao leitor uma visão geral do protótipo implementado, especialmente de sua interface e da sua capacidade funcional.

A seção 4.2 é dedicada à apresentação de uma visão geral da interface. Na seção 4.3 tem-se um exemplo de uma sessão com o browser. Para finalizar, na seção 4.4 são comentadas algumas limitações do sistema implementado.

\subsection{Visão Geral da Interface}

A interface implementada utiliza-se do conceito de janelas. Tem-se uma janela principal associada ao sistema com o rótulo "browser" e durante a execução do sistema o usuário pode solicitar a criação de outras 
janelas, contendo o diagrama correspondente à DDL da base de dados sendo investigada. Assim, tem-se a opção de exibir partes diferentes do mesmo esquema ao mesmo tempo no vídeo. A importância desta característica é que geralmente os esquemas têm um número grande de entidades e relacionamentos entre as entidades, o que dificulta a visualização do diagrama todo ou de um número significativo de objetos do esquema em estudo.

Um recurso muito utilizado num sistema interativo do tipo do browser é o mouse, pois a localização do seu cursor informa ao sistema qual janela vai receber as entradas do usuário e estas entradas são feitas principalmente através do manuseio dos botões do mouse, criando-se eventos tais como: botão esquerdo pressionado, botão esquerdo solto, etc. Um caso típico de seleção de entrada utilizada no browser é a escolha de um item num menu, o qual é apresentado de forma padronizada quando o botão direito do mouse for pressionado.

Para iniciar a execução do browser, um conceito importante a ser ressaltado é o conceito de direito de acesso a um base de dados, que é um conjunto de informações mantidas pelo sistema para cada esquema armazenado e estas informações permitem ao sistema identificar se um usuário pode ou não ter acesso a um esquema armazenado na base de dados.

- A cada base de dados existente é associado um proprietário, que pode ser um grupo de usuários ou um usuário. Diz-se que uma base de dados é pública caso pertença aos primeiro, e privada, caso contrário. Além disso, é permitido que se crie uma hierarquia de grupos de usuários, ou seja, grupos podem fazer parte de outros grupos, sendo que os grupos de mais baixo nível são formados por usuários. É esta hierárquia que determina, estaticamente, os direitos de acesso de cada usuário às bases de dados.

Os principais tipos de direitos de acesso existentes são:

- escrita: é o direito unicamente do proprietário da base de dados e que pode realizar qualquer operação sobre a mesma.

- leitura: o direito de leitura é garantido a todos os membros diretos e indiretos de um grupo de usuários com relação a todas as bases de dados deste grupo. 
Para o usuário pesquisar uma base de dados via browser é necessário que ele tenha acesso, pelo menos, o direito de acesso para leitura sobre a base de dados.

\subsection{Exemplo de Utilização do Browser}

Apresenta-se nesta seção um exemplo de uma sessão com o browser. Será utilizado nesse exemplo o esquema de uma base de dados cujo diagrama correspondente foi apresentado no capitulo anterior, na figura 3.3. $\mathrm{O}$ arquivo de entrada de dados para a construção do diagrama é apresentado no apêndice $B$.

Para iniciar uma sessão com o browser é necessário estar com - Sistema de Gerenciamento de Janelas SunView em funcionamento e em alguma das janelas de comandos digitar o comando "browser". O sistema nesse instante vai exibir algumas mensagens, pedindo ao usuário para entrar com o nome do esquema, o qual quer ter acesso e também o nome do arquivo de entrada, arquivo que contém informaçôes correspon 'ntes ao diagrama associado ao esquema. Caso esteja correto o nome do arquivo de dados e o usuário tenha acesso ao esquema é então criada uma janela para o browser, que será referenciada como janela principal do browser, e tem-se um menu associado a ela. Este menu aparecerá quando for pressionado o botão direito do mouse dentro da janela principal do browser.

Após ter sido criada a janela principal do browser, o usuário poderá solicitar a criação de janelas para ver o diagrama associado à DDL da base de dados escolhida. Esta opção é selecionada através da opção "ver esquema da BD", oferecida no menu da janela principal do browser (ver figura 4.1). A localização da nova janela criada dentro da janela principal do browser tem uma ordem pré-estabelecida pelo sistema mas, caso o usuário deseje, poderá alterar a seu critério a localização, assim como também poderá modificar as dimensões de uma janela através de opções oferecidas no menu da janela.

Após ter criado o número de janelas desejado, estas janelas serão exibidas simultaneamente dentro da janela principal do browser e a 


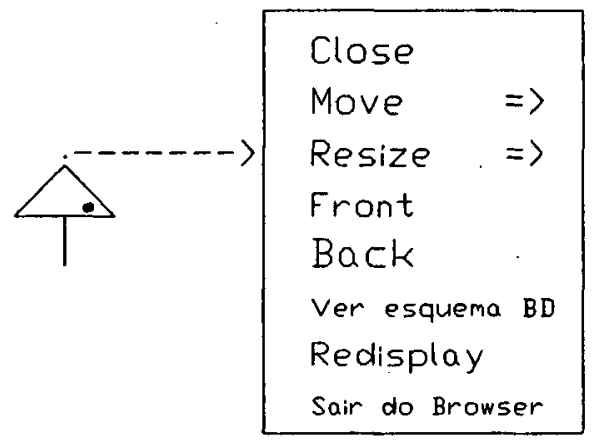

Figura 4.1: "Menu de fundo" da janela principal do browser

janela que receberá o sinal do mouse para alguma ação será a janela onde estiver posionado o seu cursor. Na figura 4.2 é apresentada uma situação onde já foi escolhido um esquema para analisar. Este esquema existe e o usuário tem acesso a ele e já solicitou a criação de duas janelas para ver o diagrama associado ao esquema.

Nas janelas criadas para mostrar o diagrama do esquema armazenado na base de dados tem-se em suas laterais uma barra para que o usuário realize funções de "scroll" para ver partes do esquema que não estão sendo exibidas. Este "scroll" é possível tanto na vertical como na horizontal. As opções de "scroll" são realizadas após o usuário entrar com o cursor do mouse numa das regióes das barras de "scroll" e pressionar o botão esquerdo ou direito do mouse. Pressionando o botão direito haverá um deslocamento à direita do desenho se estiver numa região horizontal e um deslocamento na parte inferior do desenho se estiver numa região vertical. Para o botão 


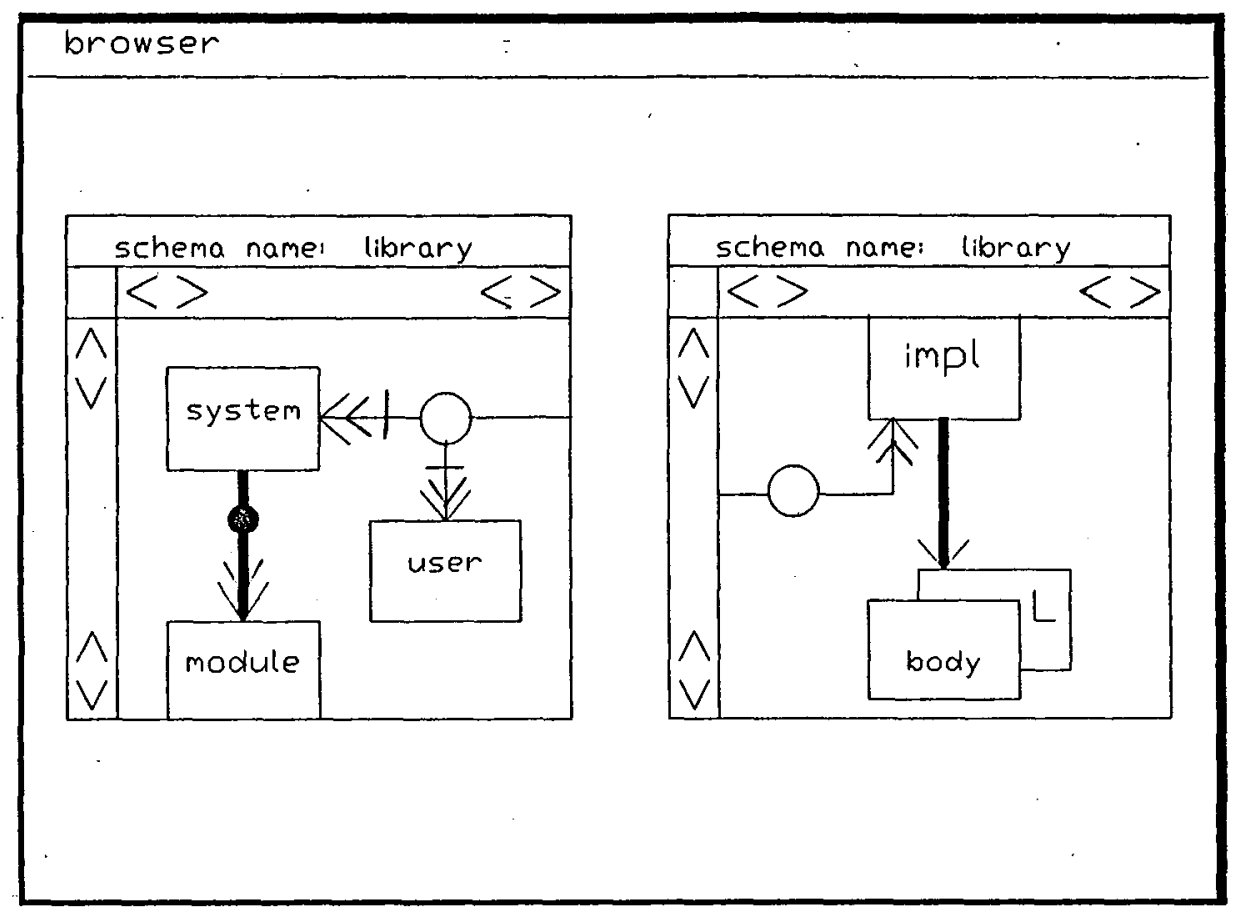

Figura 4.2: Janela principal do browser após selecionada a opção "Ver esquema BD"

esquerdo, tem-se uma ação análoga, um deslocamento à esquerda ou um deslocamento na parte superior do desenho.

A janela principal do browser é uma janela dentro do sistema de Gerenciamento de janelas SunView e poderá haver outras janelas do sistema que estarão abertas no instante em que o browser estiver em execução. Assim, o usuário pode executar o seu programa de aplicação e logo em seguida acionar o browser.

O diagrama mostrado nas janelas criadas na figura 4.1 corresponde ao nível geral do browser. Neste nivel tem-se quatro tipos diferentes de menus que poderão aparecer numa janela de nível geral. Na figura 4.3 apresenta-se um desenho correspondente a esses menus. $O$ "menu de janela" 


\begin{tabular}{|l|} 
Done \\
Move $\quad \Rightarrow$ \\
Resize $\Rightarrow$ \\
Front \\
Back \\
Props \\
Redisplay \\
\hline
\end{tabular}

(a) - "memu de janela"

\section{Relaclonamentos}

Atributos

Versao

Instanclas

(c) - "menu de entidade"
Selecionar Entidade

Selecionar Relocionamento

Ver Pilha Entidades

Destruir Janela

(b) - "menu de fundo"

Nome Relacionamento

Atributos

Entidades Participantes

Instancias

(d) - "menu de relacionamento"

Figura 4.3: Menus associados à janela do nível geral

será apresentado quando for pressionado o botão direito do mouse (esta ação será representada pelo símbolo $A_{\text {) }}$ ) sobre as bordas da janela (ver figura 4.4). Entre as opções desse menu tem-se a opção de mover ou redimensionar a janela. 


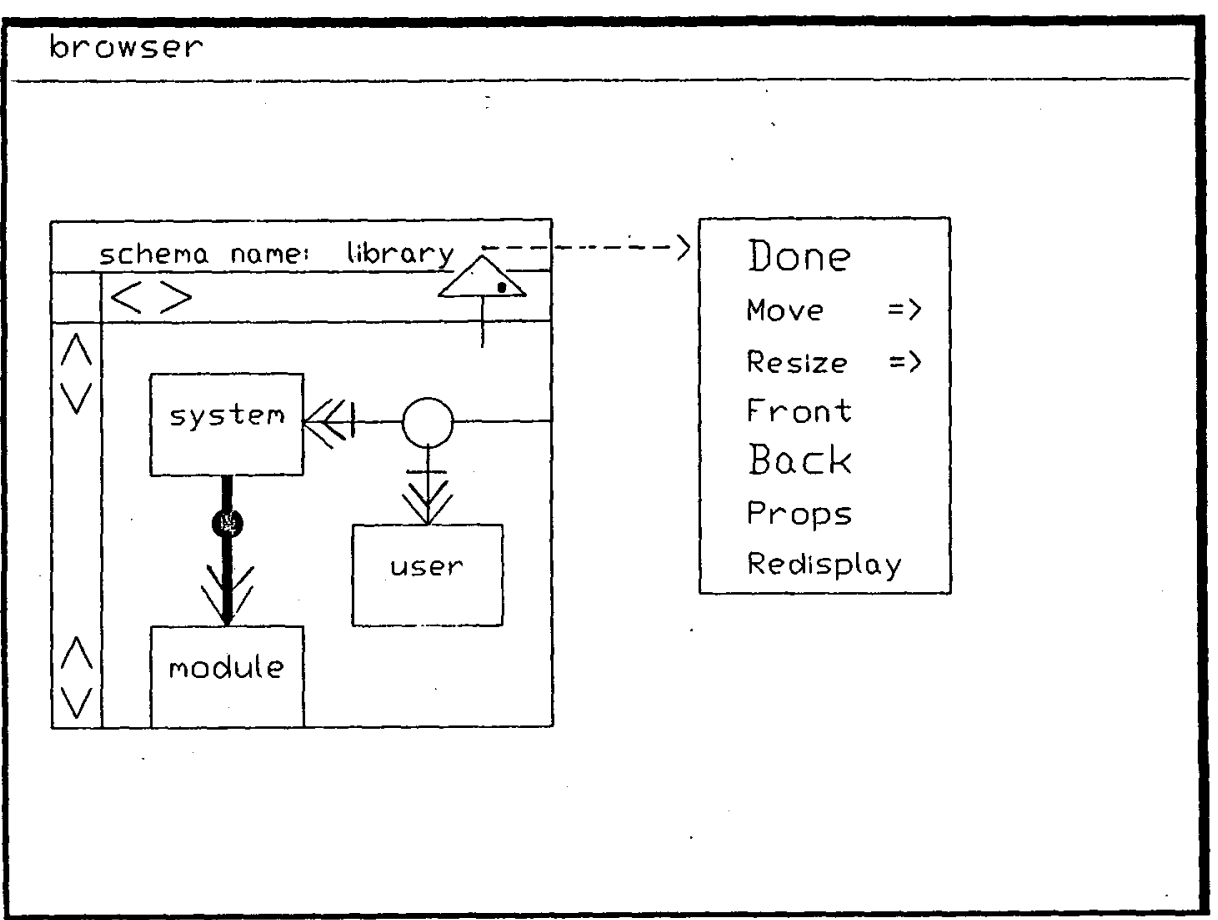

Figura 4.4: "Menu de janela" associado a janela do nível geral

O item (b) apresentado na figura 4.3 corresponde ao "menu de fundo", que será apresentado caso o usuário pressione o botão direito do mouse na área interior a uma janela de nível geral e o ponto localizado pelo cursor do mouse não esteja sobre o desenho de uma entidade ou de um relacionamento do esquema. A opção "selecionar entidade", quando escolhida (ver figura 4.5), vai criar uma janela "pop-up", onde o usuário digitará o nome da entidade desejada (ver figura 4.6). Caso a entidade escolhida exista, ela será exibida na tela (ver figura 4.7), caso contrário, será exibida a mensagem "não existe entidade com este nome" e o usuário terá op̧̧ão de escolher outra entidade ou desistir dessa operação. Tem-se uma ação análoga quando a opção escolhida for "selecionar relacionamento". 


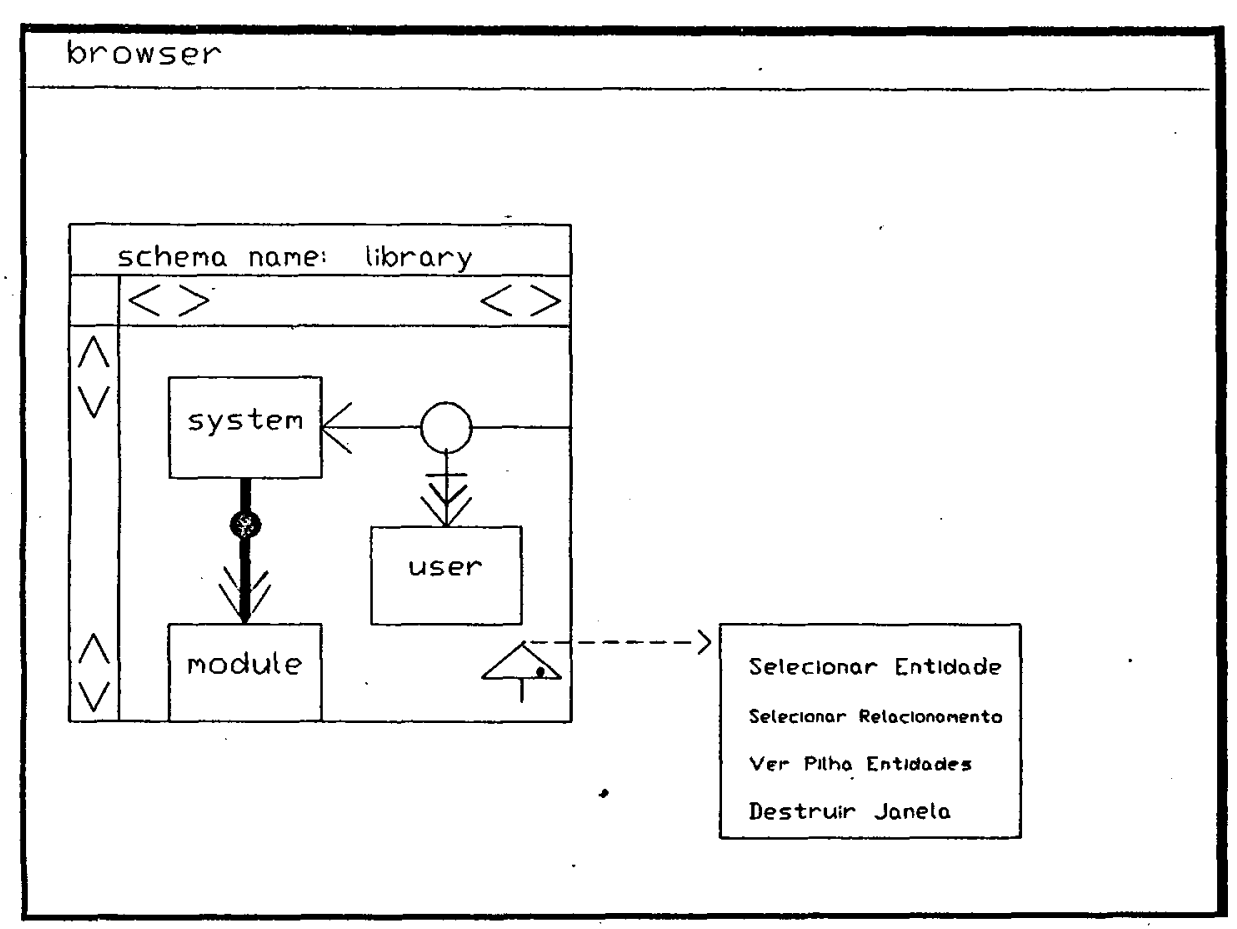

Figura 4.5: "Menu de fundo" da janela do nível geral 
A terceira opção do menu de fundo permite exibir uma pilha onde aparecem os nomes dos últimos objetos do esquema que tiveram as suas intâncias analisadas via browser, esta opção serve como um histórico para o usuário saber quais os objetos já analisados durante a sessão com o browser. Também é oferecida a opção para "destruir janela" caso o usuário não tenha mais interesse numa determinada janela de nível geral.

O "menu de entidade" será apresentado quando o usuário pressionar o botão direito do mouse sobre o desenho correspondente a uma entidade. Ver exemplo na figura 4.8. Neste menu, a opção "atributos" mostrará uma nova janela "pop-up" cujo conteúdo será o nome dos atributos da entidade selecionada (ver figura 4.9). Tem-se uma opção para o usuário dar continuidade à execução. Quando o usuário selecionar a opção "relacionamento" é necessário que o usuário pressione uma segunda vez o botão direito do mouse para que o sistema mostre um menu contendo todos os relacionamentos em que a entidade selecionada participa. Se o usuário quiser navegar no esquema ele pode selecionar o nome de um dos relacionamentos apresentados e então o sistema mostrará o relacionamento na respectiva janela, caso este relacionamento não esteja sendo exibido. 


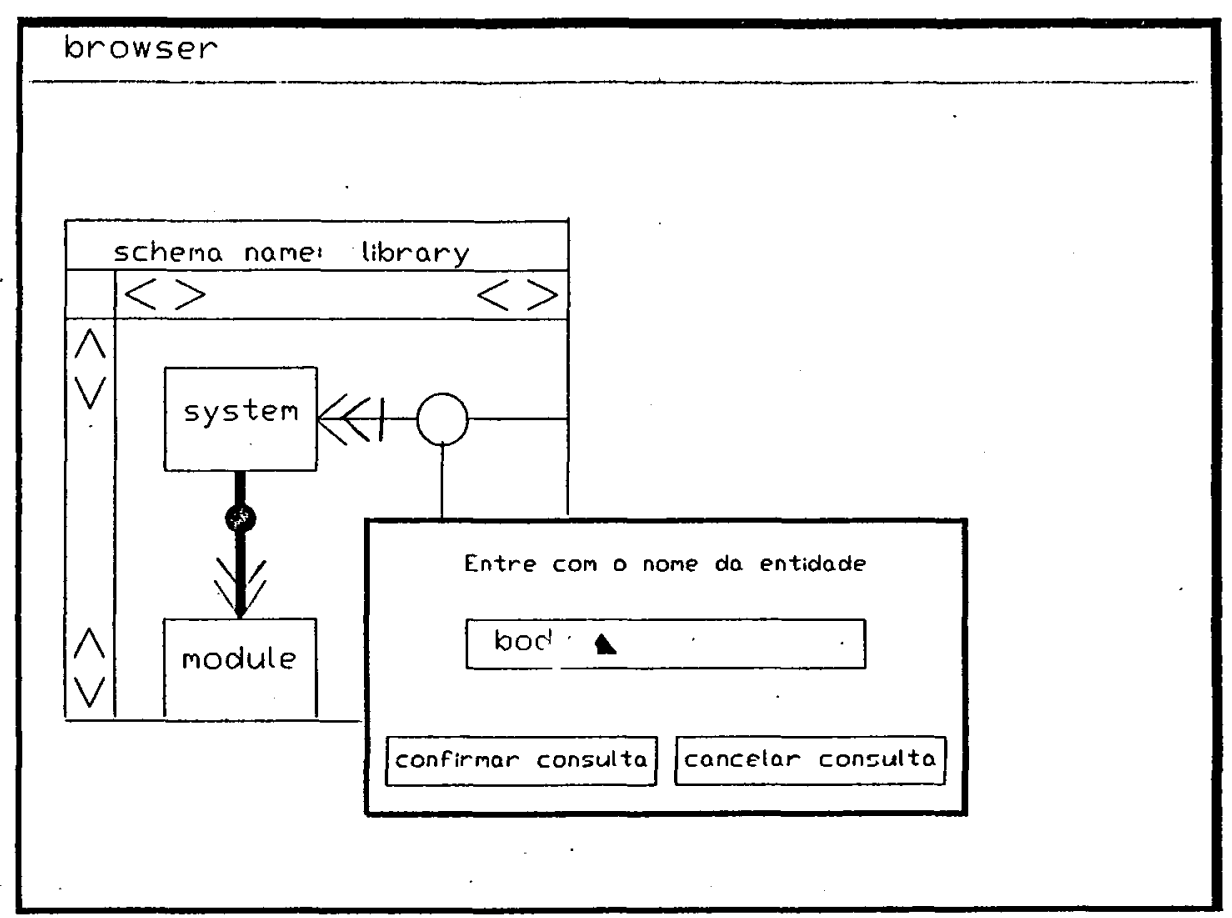

Figura 4.6: Janela "pop-up" associada à opção "selecionar entidade" 


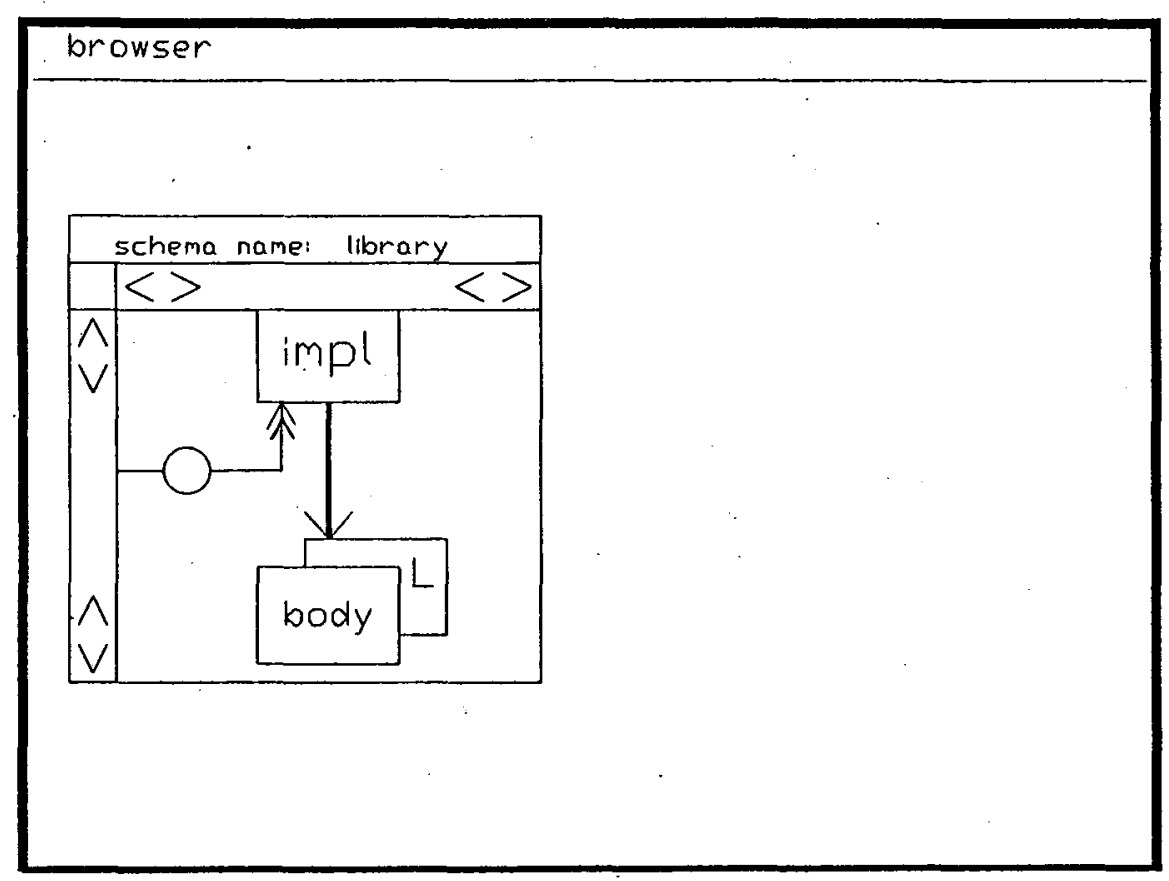

Figura 4.7: Janela de nível geral após seleção da entidade "body" 
Tem-se também a opção "instâncias" no menu de entidade, que quando selecionada permite mudar de nível no browser (ver figura 4.10). O novo nível apresentado será o "Nivel de Instâncias". Nesse nível, conforme visto na seção Modelo de Dados usado no Browser, são mostradas as instâncias, do tipo da entidade selecionada, que estão armazenadas na base de dados em estudo. No nível de instâncias é oferecida opção de "scroll" vertical para o usuário ver o conteúdo das instâncias que não estão aparecendo na tela.

Para o "menu de relacionamento", ver exemplo na figura 4.11, tem-se duas opções análogas ao menu de entidades, que são: "atributos" e "instâncias". A opção "nome relacionamento" vai exibir o nome do relacionamento selecionado (ver figura 4.12).

O nome do relacionamento não foi apresentado no Nível Geral para não sobrecarregar a notação. Outra opção do menu de relacionamento é "entidades participantes". É necessário que o usuário pressione uma segunda vez o botão direito do mouse para que o sistema mostre todas as entidades que participam do relacionamento e também seus respectivos papéis no relacionamento (ver figura 4.13). Se o usuário selecionar alguma entidade do menu mostrado, o sistema vai apresentar na tela a entidade desejada caso ela já não esteja. Caso o usuário deseje continuar a execução do sistema sem navegar no esquema, ele precisa pressionar o botão direito do mouse fora do menu apresentado.

Após o usuário ter executado todas as ações desejadas sobre uma janela, ele poderá optar por apagar apenas aquela janela do sistema através da op̧̧ão "destruir janela" no menu de fundo da janela; ou caso queira sair do browser é oferecida uma opção no menu de fundo da janela principal do browser. 


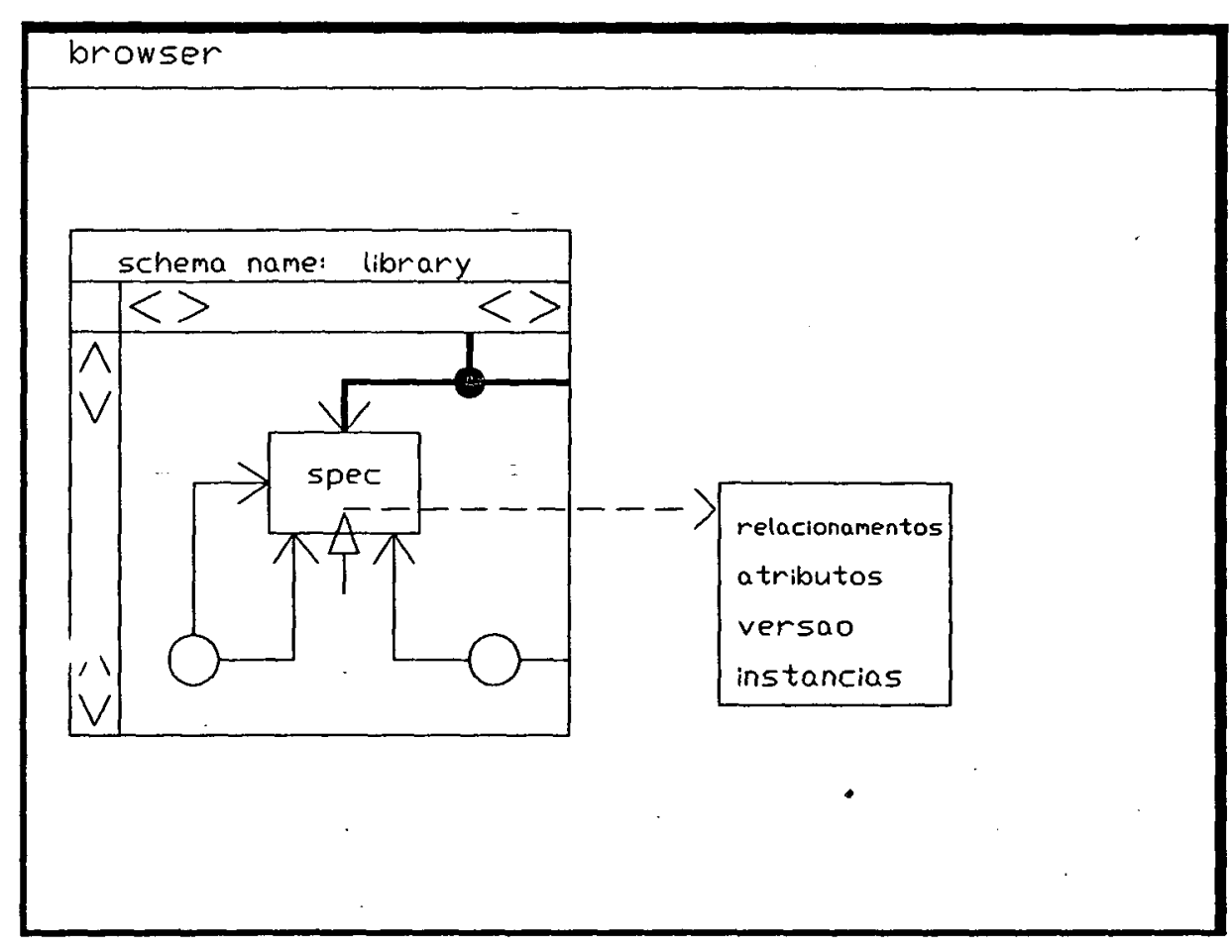

Figura 4.8: "Menu de entidade" 


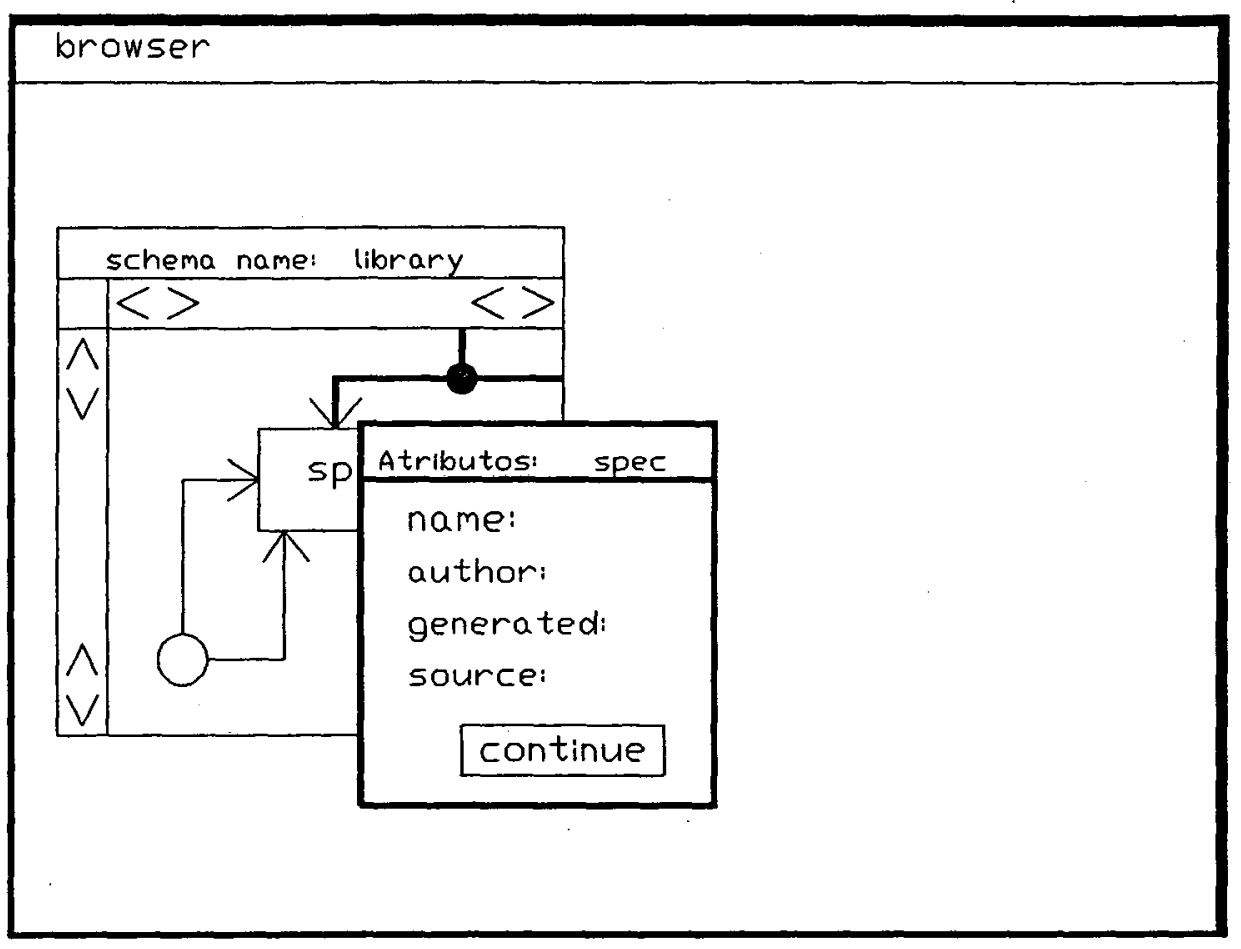

Figura 4.9: Escolha da opção "atributos" no "menu de entidade" 


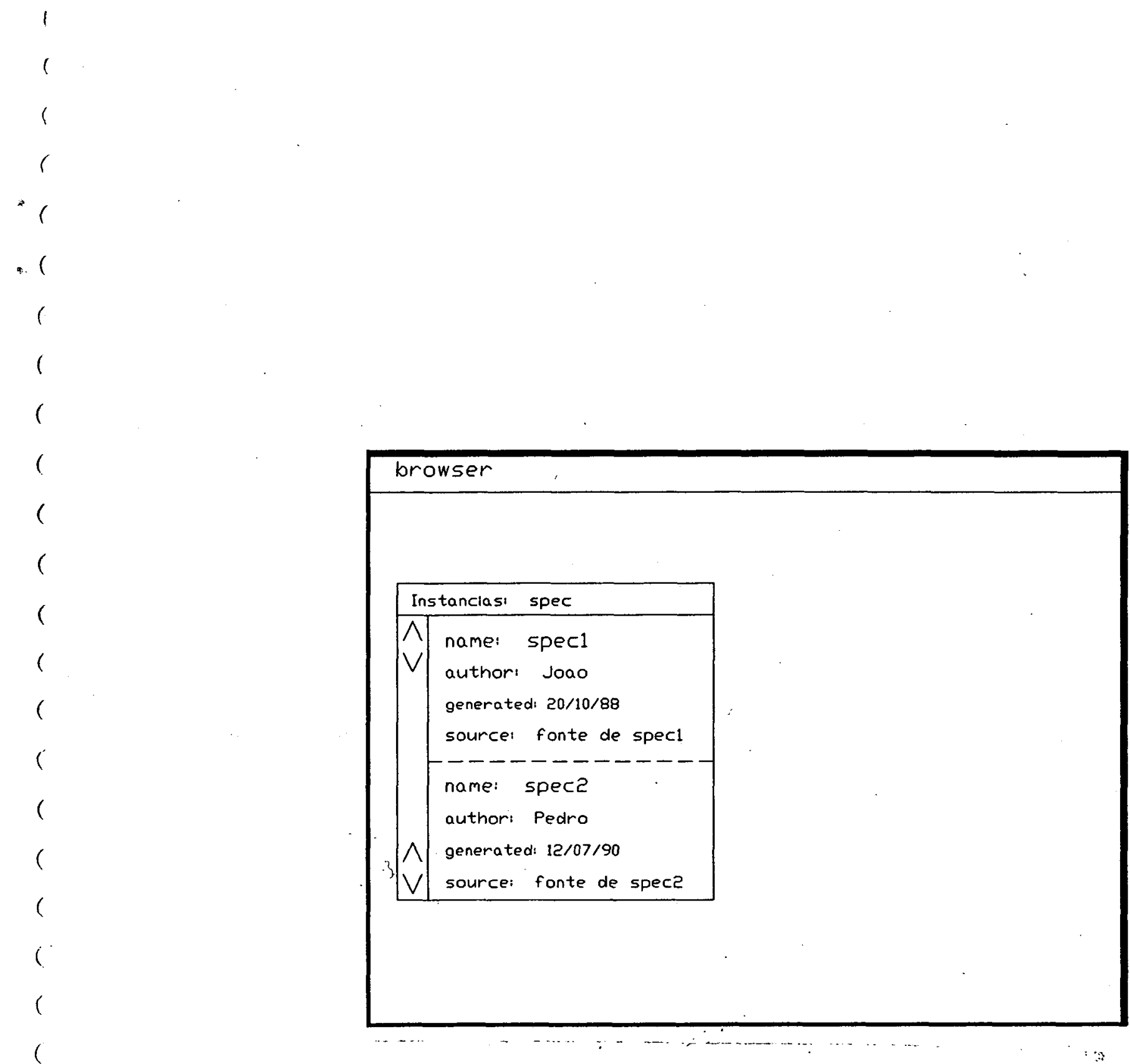

Figura 4.10: Nível de instâncias selecionado 


\section{browser}

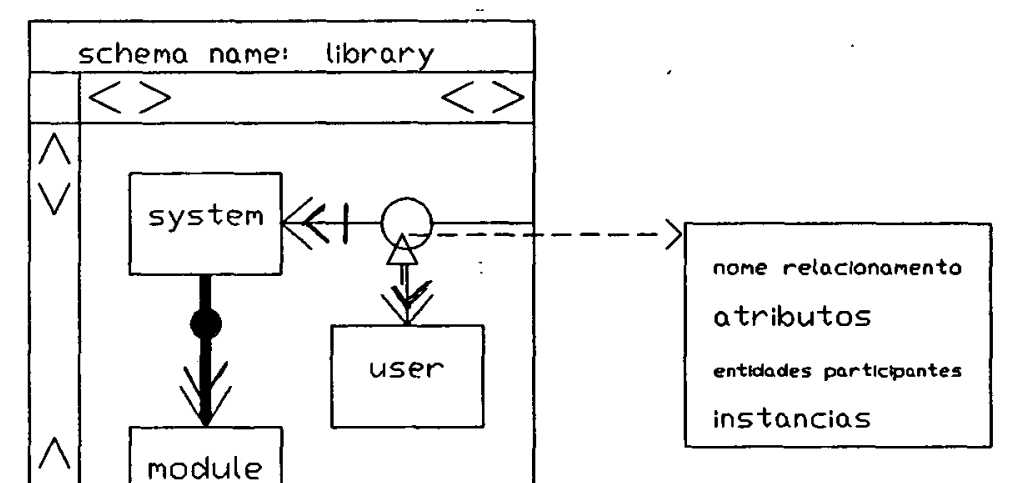

Figura 4.11: "Menu de relacionamento" 


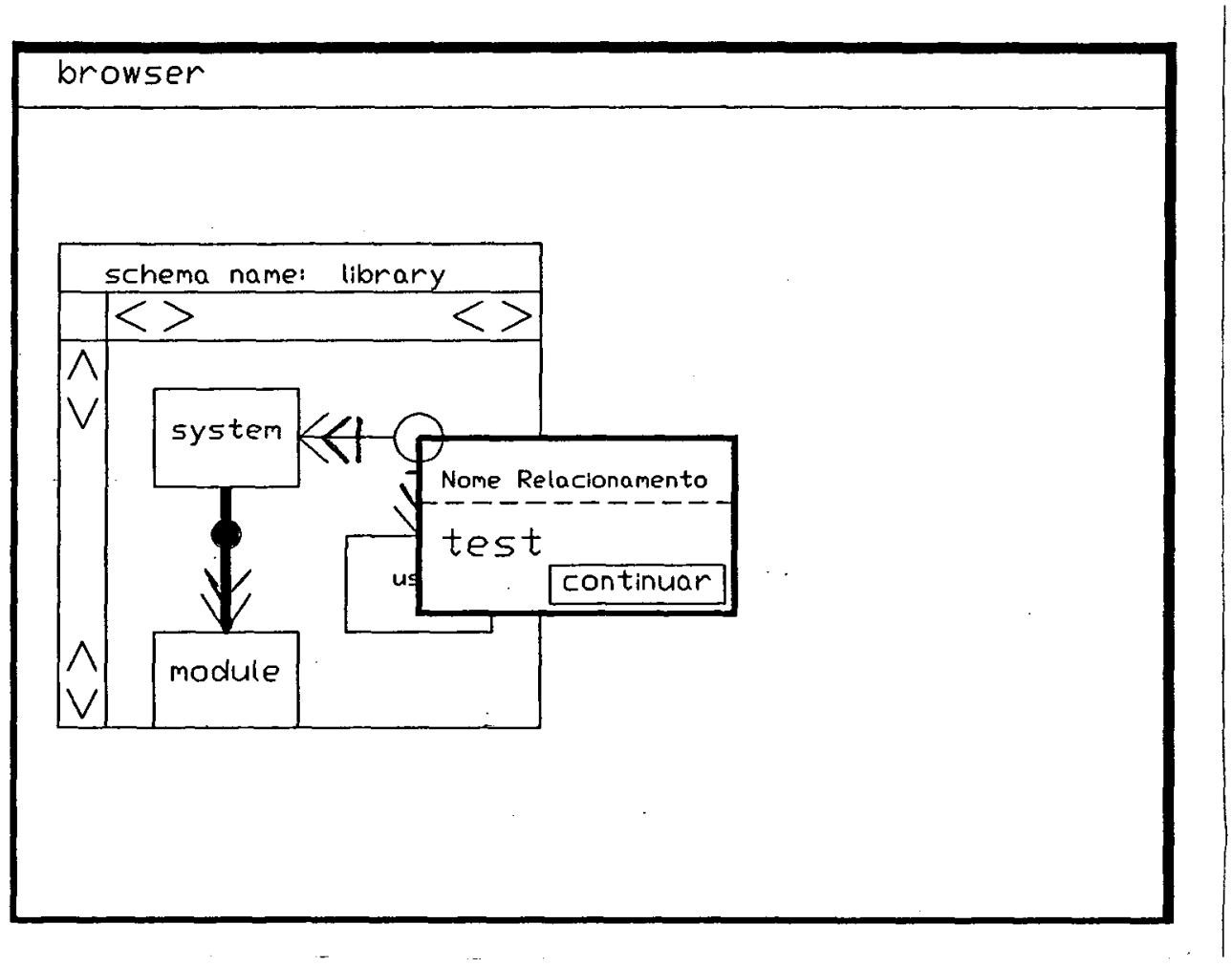

Figura 4.12: Seleção da opção "nome relacionamento" no "menu de relacionamento" 


\section{4 : Limitações do Browser Implementado}

Nesta seção são analisadas algumas limitações do protótipo de browser implementado para a dissertação de mestrado. Um dos fatores limitantes vem do SGBD que foi utilizado, pois, no SGBD Damokles, os esquemas só podem ser definidos estaticamente, isto é, não há facilidades para definir novos tipos de dados ou que permitam a alteração do esquema original em tempo de execução. Assim, no protótipo implementado não são oferecidos recursos para a definição ou alteração do esquema da base de dados durante a execução do browser.

Um outro fator limitante a ser ressaltado quanto ao SGBD utilizado é o fato da versão do Damokles utilizada ser monousuária, isto é, não existe um controlador para gerenciar as instâncias. Como consequência, o conteúdo das instâncias apresentadas no browser é o conteúdo do momento de abertura da base de dados.

O sistema de gerenciamento de janelas SunView utilizado na implementação do protótipo do browser também impôs algumas restrições ao protótipo. No SunView tem-se um número muito limitado de descritores de arquivos que são utilizados para janelas, estando disponíveis apenas 64 descritores, o que restringe o número de janelas de nível geral que o usuário pode criar durante a utilização da interface.

A falta de uma função do tipo "zoom" no browser é uma limitação que pode ser resolvida numa versão posterior do protótipo. Foi estudado o pacote gráfico SunCore[SCo_88], disponível na estação de trabalho Sun, para a implementação de uma função oferecendo "zoom" no browser, mas ocorreram problemas de interface entre os pacotes SunCore e SunView, o que impossibilitou a sua implementação nesta primeira versão do protótipo.

\subsection{Considerações Finais}

Neste capítulo foi apresentado com mais detalhes o browser desenvolvido. Foram mostrados, através de um exemplo, as principais carac- 


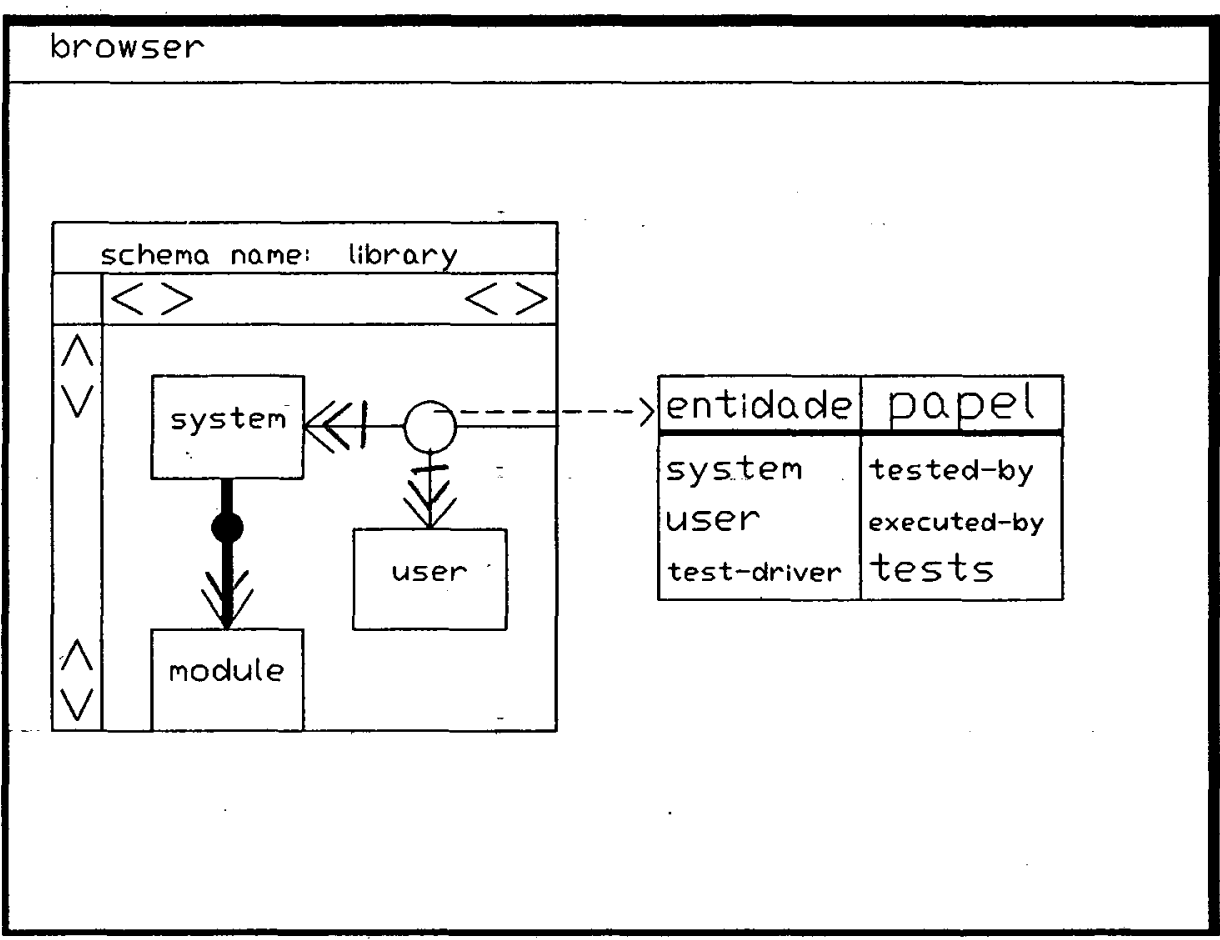

Figura 4.13: Seleção da opçã̀o "entidades participantes" no "menu de relacionamento" 
terísticas do sistema.

A revisão bibliográfica realizada sobre os browsers disponíveis na literatura foi de importância fundamental para fazer um levantamento das principais características de uma interface do tipo browser. Levando-se em consideração as limitações de tempo e recursos humanos, não foi possível implementar, na primeira versão do protótipo, todas as características levantadas na revisão bibliográfica. No próximo capítulo são apresentadas algumas sugestões para o protótipo, as quais poderão ser incorporadas em versões futuras do sistema desenvolvido. 


\section{Capítulo 5}

\section{Conclusão}

\subsection{Avaliação do Protótipo}

De acordo com as características levantadas para um browser, apresentadas no início desta dissertação, $\mathrm{p}$ ì-se concluir que o protótipo implementado atende à maioria desses requisitos.

A interface implementada pode ser utilizada para suprir a falta de uma linguagem de consulta no SGBD Damokles. É uma ferramenta que auxilia o usuário da base de dados Damokles, permitindo a navegação na base de dados tanto a nível de esquema quanto a nível de instâncias. Outra utilização importante dessa interface é facilitar a depuração de programas que utilizam o Damokles. Caso não tivesse uma ferramenta com esta funcionalidade, o usuário da base de dados teria que desenvolver um programa de aplicação para pesquisar e imprimir o conteúdo das bases de dados e assim certificar-se se as operações realizadas sobre as bases de dados estão corretas.

Um ponto importante a ser ressaltado na interface implementada é a utilização de reçursos gráficos para a interface com o usuário. Estes recursos são utilizados para apresentar um diagrama correspondente a descrição do esquema, cujo conteúdo está armazenado na meta base de dados. A apresentação do diagrama é muito importante para facilitar a compreensão 
do esquema pelo usuário, permitindo uma boa visualização dos objetos do esquema, principalmente para os objetos compostos.

Esta interface foi desenvolvida com o propósito de ser uma maneira simples de um usuário navegar na base de dados, permitindo a visualização dos objetos do esquema e também os relacionamentos entre eles. Procurou-se desenvolver uma interface de fácil utilização e de aprendizagem rápida, é necessário apenas que o usuário tenha um mínimo de conhecimento de um ambiente de janelas, pois na execução da interface utiliza-se o mouse e as opções do sistema são oferecidas através de vários tipos de menus.

Os testes realizados com uma base de dados de pequeno porte não revelaram nenhum problema referente a tempo de resposta de acesso às instâncias dos objetos na base, mas testes adicionais com bases de dados reais deverão ser realizadas no futuro.

\subsection{Sugestão para Evolução do Protótipo e Novas Pesquisas}

Nesta seção, apresentam-se algumas características que podem ser incorporadas à versões futuras do protótipo implementado.

Um ponto importante para a evolução do protótipo é a necessidade de se reescrever esta interface para um outro sistema de gerenciamento de janelas onde a base desse novo sistema seja o X-Window. Pode-se citar que o sistema X-View disponível para a estação de trabalho Sun satifaz as características desejadas e não foi utilizado porque não se encontrava disponível no início da implementação deste trabalho. A importância dessa mudança se prende ao fato de que seria mais fácil a integração com outras ferramentas, para oferecer mais recursos ao usuário da interface. Como exemplo disso, uma função do tipo "zoom" seria mais fácil de ser implementada na interface. Seria resolvido também o problema de limitação do número de janelas na interface, problema que não ocorre num sistema com suporte do X-Window.

Para a evolução do protótipo pode-se criar um novo módulo, que seria responsável pelo gerenciamento de alguns parâmetros do sistema. 
$\mathrm{Na}$ estrutura diagramática da arquitetura geral do sistema, apresentada no capítulo 3, ele estaria interagindo com o módulo Controlador Geral e não seria necessário a utilização do buffer, pois o novo módulo teria funções para armazenar e recuperar da base de dados os valores dos parâmetros. Entre os parâmetros que poderiam ser gerenciados por este módulo pode-se citar, por exemplo, diferentes cores, dimensões e formas para os objetos.

Uma característica que deve ser incorporada ao protótipo é referente às consultas nas instâncias da base de dados. É importante poder oferecer restrições sobre as instâncias a serem mostradas, permitindo ao usuário formular consultas mais complexas.

Como sugestão para outras pesquisas levando a melhoria no ambiente Damokles, pode-se considerar a necessidade de um sistema para gerar automaticamente o diagrama correspondente à descrição da base de dados, sem a necessidade do arquivo de entrada fornecido pelo usuário, ou então uma interface gráfica para permitir a própria definição do esquema. 


\section{Bibliografia}

[Abi_74] ABRIAL, J. R. Data semantics. Data Base Management, Amsterdam, North-Holland, 1974. p.1-59

[Abr_87a] ABRANIWICZ, K. et al. The DAMOKLES DDL user manual. Karlsruhe, Forschungszentrum Informatik, 1987

[Abr_87b] ABRANIWICZ, K. et al. The DAMOKLES DML user manual. Karlsruhe, Forschungszentrum Informatik, 1987

[Bac_69] BACHMAN, C. W. Data Structure Diagrams, Data Base, J. ACM SIGBLr, 1(2):4-10, 1969

[Che_76] CHEN, P. P. The entity-relationship model - toward a unified view of data. ACM Transactions on Data Base Systems, 1(1):936, Mar.1976

[Cod_70] CODD, E. F. A relational model for large shared data banks. Commun. ACM, 13(6):377-87, Jun. 1970

[DiG_86] DITTRICH, K. R.; GOTTHARD, W.; LOCKEMANN, P. C. DAMOKLES - a database system for software engineering environments. Berlim, Springer,1986. (Lecture Notes In Computer Science, 244) p. 353-71

[Dit_86] DITTRICH, K. R. Object-Oriented Database System - A Workshop Report. In: proceedings of 5th ER Conference, Dijon, Amesterdam, North Holland, 1986

[Fis_89] FISCHER, G. Human-computer interaction software: lessons learned, challenges ahead. IEEE Software p.44-52, Jan. 1989 
[Fog_84] FOGG, D. Lesson From a "Living in a Database" Graphical Query Interface. In: proceedings of the ACM SIGMOD International Conference on the Management of Data (Boston, Mass.), 1984. p. $100-06$

[Gol_85] GOLDMAN, K. J. et al. ISIS: Interface for a Semantic Information System. In: proceedings of the ACM SIGMOD International Conference on the Management of Data, ACM, New York, 1985. p. 328-42

[Har_90] HARA, C. S. Utilização de um Banco de Dados Orientado a Objetos em um Ambiente de Desenvolvimento de Software. Tese de Mestrado, IMECC - UNICAMP, Campinas, 1990

[HMc_81] HAMMER, R. \& MCLEOD, D. SDM: A Semantic Database Model. ACM Transactions on Database Systems, 6(3):351-87, Sep. 1981

[HuK_87] HULL, R. \& KING, R. Semantic database modeling: survey, applications, and research issues. ACM Computing Surveys, 19(3):201-60, Sep. 1987

[Kin_84] KING, R. SEMBASE: a semantic DBMS. In: proceedings of the First International Workshop on Expert Database Systems, Univ. of Southern Carolina, Columbia, S. C., Oct. 1984, p. 15171

[Mel_88] MELO, R. N. Banco de dados não convencionais: a tecnologia do BD e suas novas áreas de aplicação. VI Escola de Computação, Campinas, 1988

[Pim_89] PIMENTA, M. S. O sistema DAMOKLES. Banco de Dados para aplicações não convencionais. IV EBAI, Termas de Rio Hondo, Argentina, 1989. p. 123-46

[SCG_88] SunCGI Reference Manual. Sun Microsystems, 1988

[SCo_88] SunCORE Reference Manual. Sun Microsystems, 1988

[Smi_77a] SMITH, J. M. \& SMITH, D. P. Database abstractions: aggregations. Comunications of ACM, 20(6):405-13, Jun. 1977 
[Smi_77b] _ SMITH, J. M. \& SMITH, D. P. Database abstractions: agregations and generalization. ACM Transactions on Database System, 2(2):105-33, Jun. 1977

[SVi_88] SunVIEW 1 programer's guide. Sun Microsystems, 1988

[Tra_86] TRAINA Jr., C. Modelo de dados e máquina dedicada para aplicações de engenharia. Tese de Doutorado, Depto. de Física e Ciência dos Materiais, São Carlos, 1986

[WoK_82] WONG, H. K. T. \& KOU, I. GUIDE: A Graphical User Interface for Database Exploration. In proceedings of 8th International Conference on Very Large Data Bases. Very Large Data Base Endowment, Saratoga, California, 1982. p. 22-32 


\section{Apêndice A}

\section{Exemplo de definição de um esquema}

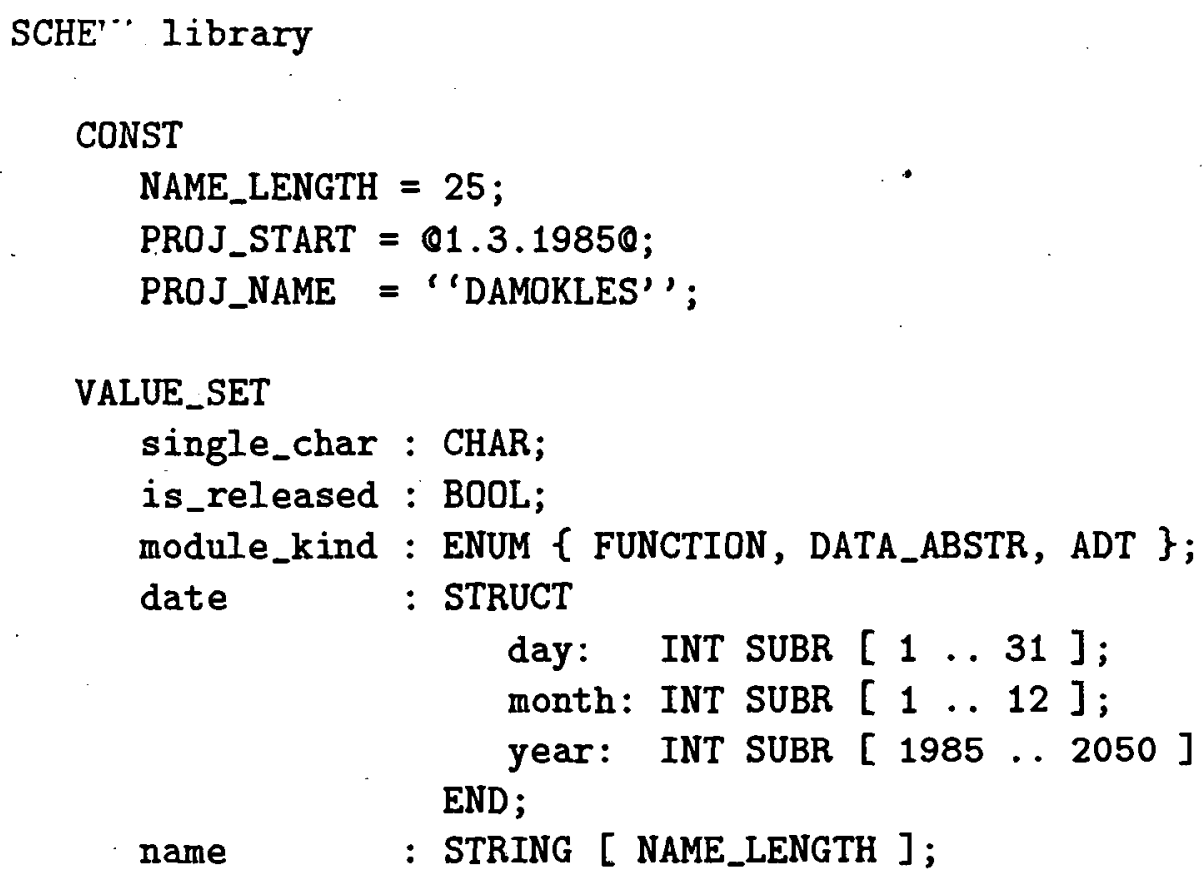


OBJECT TYPE user

ATTRIBUTES

$\begin{array}{ll}\text { name: } & \text { name; } \\ \text { birthday: } & \text { date; } \\ \text { employment: } & \text { name }\end{array}$

END user;

OBJECT TYPE module

ATTRIBUTES

$\begin{array}{ll}\text { name: } & \text { name; } \\ \text { project: } & \text { name; } \\ \text { compiled: } & \text { date; } \\ \text { mod_kind: } & \text { module_kind } \\ & \end{array}$

spec, impl, includes

END module;

OBJECT TYPE test_driver

ATTRIBUTES

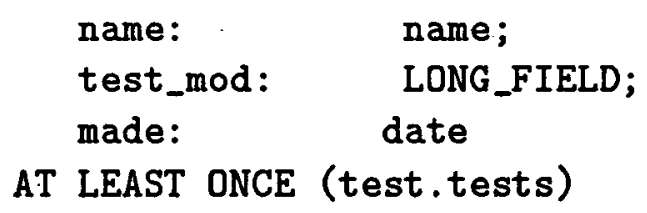

AT LEAST ONCE (test.tests)

END test_driver;

SYNONYM package FOR module;

OBJECT TYPE impl

IS UNION OF body, body. VERSION

AT LEAST ONCE ( includes.import )

END impl;

OBJECT TYPE body

ATTRIBUTES

name: name; 


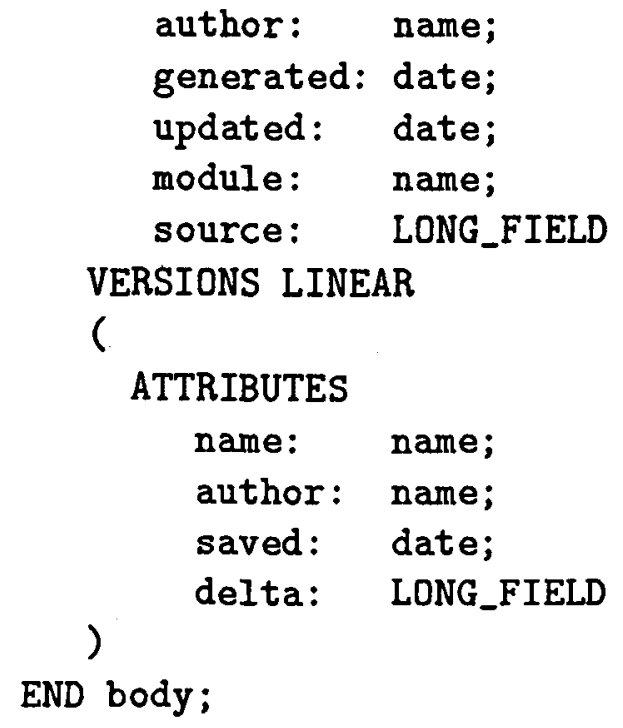




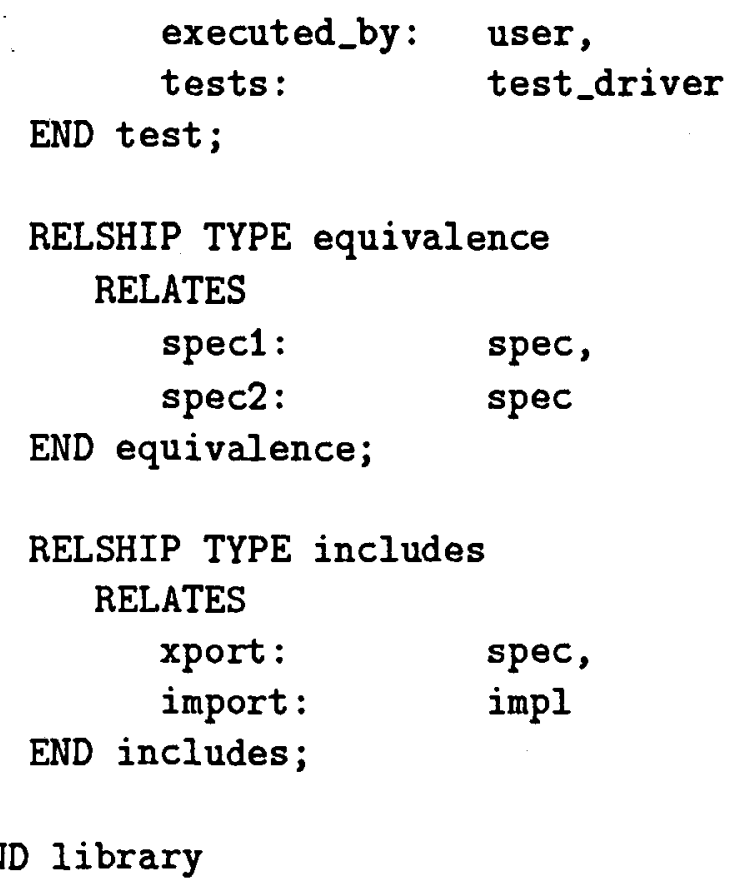




\section{Apêndice B}

\section{Entrada Para a Criação do Diagrama do Modelo de Dados Usado no Browser}

$\mathrm{O}$ arquivo de entrada para o modelo de dados utilizado no exemplo apresentado no capítulo 4 é o seguinte:

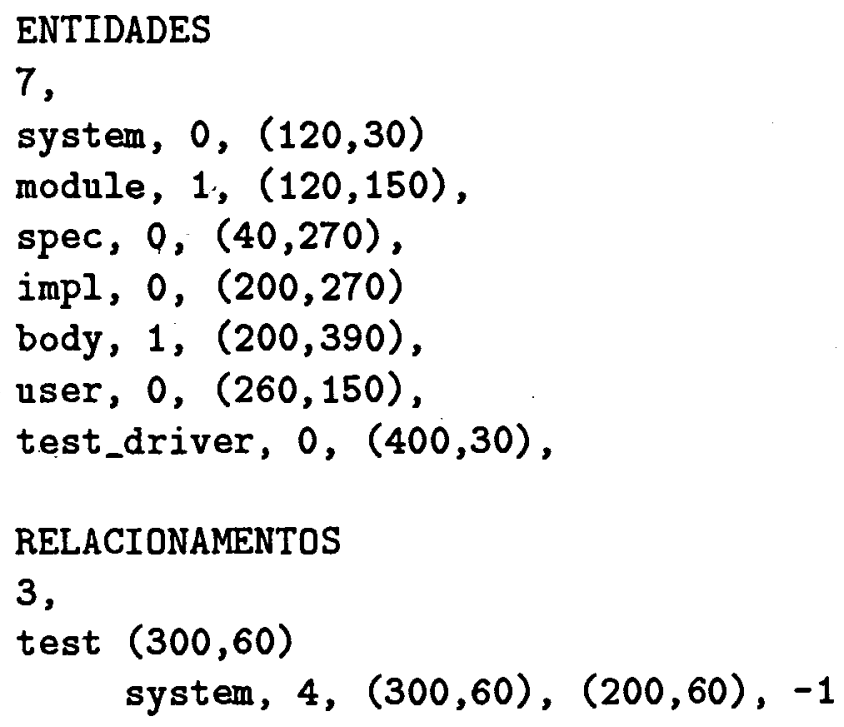




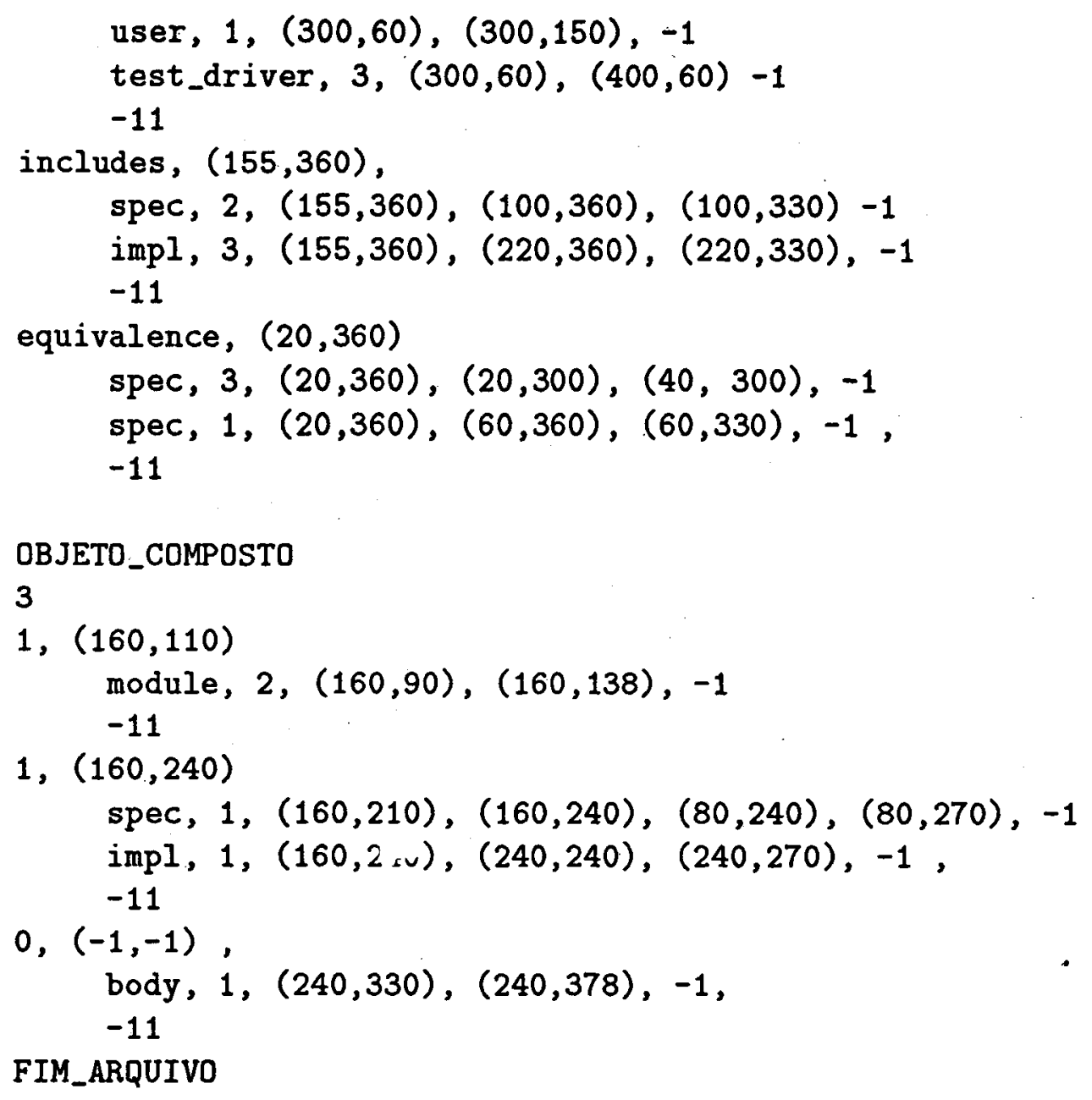

O programa que interpreta os dados acima e gera o diagrama correspondente ao modelo de dados funciona conforme se explica seguir.

Tem-se um mini-analisador lexico que reconhece os ítens do arquivo de entrada. Se o ítem reconhecido é um tipo de objeto tem-se uma das seguintes condições.

Se o objeto a ser analisado é uma entidade então tem-se o nome da entidade, por exemplo a entidade "system" é a primeira entidade num total de sete. $O$ próximo ítem é um número entre zero e três. $O$ zero 
indica que esta entidade não possui versão. Se o número está entre um e três, corresponde a uma entidade com versão e o tipo da versão pode ser linear (L), árvore (T) ou acíclico (A). Para finalizar a linha correspondente a uma entidade, tem-se um par ordenado $(x, y)$ correspondente ao ponto do canto superior esquerdo do desenho que representa a entidade.

Se o objeto a ser iterpretado no arquivo de entrada é um RELACIONAMENTO, tem-se o nome do relacionamento e um ponto de coordenadas $(x, y)$ indicando o centro do círculo que representa este relacionamento. Nas linhas posteriores é apresentado o nome das entidades participantes, um número entre zero e quatro representado a cardinalidade dessa entidade no relacionamento e um conjunto de pontos que serão ligados para formar o arco que representa o relacionamento. $O$ primeiro destes pontos é o centro do círculo que representa o relacionamento e o último é um ponto que pertence a entidade cujo nome foi apresentado no início da linha. O final de um conjunto de pontos é representado pelo número -1 e o final de um relacionamento é representado pelo número -11 .

Caso o objeto interpretado seja um OBJETO_COMPOSTO, tem-se no início da descricão do objeto um número que é zero ou um. Se for zero tem-se um objeto composto do tipo UNION, caso contrário, tem-se um objeto composto do tipo STRUCTURE.

Para um objeto composto do tipo STRUCTURE tem-se um ponto representando onde será desenhado um pequeno círculo sobre o arco que representa quais entidades participam deste objeto composto. No exemplo acima, tem-se que o primeiro objeto composto é um STRUCTURE e o ponto $(160,120)$ é o local onde será desenhado um círculo representando o tipo deste objeto composto. Tem-se também o nome da entidade participante, "module", um número indicando a cardinalidade desta entidade no objeto composto e um conjunto de pontos utilizados para traçar o arco que representa este objeto. Para finalizar um conjunto de pontos é utilizado o número -1 e para indicar o final de um objeto composto é utilizado o número -11 .

Caso o objeto composto seje do tipo UNION, a diferença para o caso anterior é que não será necessário o ponto para o desenho do círculo, 
neste caso, tem-se o ponto $(-1,-1)$. Para finalizar o aquivo de entrada tem-se o ítem léxico FIM_ARQUIVO. 